Research Article

\title{
Experimental Investigation on Flexural Behavior of Granite Stone Slabs with Near Surface Mounted CFRP Bars and Screw-Thread Steels
}

\author{
Xiaopeng Gao, ${ }^{1}$ Zhongfan Chen ${ }^{D},{ }^{1}$ Xiaomeng Ding, ${ }^{1}$ and Erxiang Dong ${ }^{2}$ \\ ${ }^{1}$ Key Laboratory of RC and PC Structures of Ministry of Education, Southeast University, Nanjing 210096, China \\ ${ }^{2}$ Nanjing Yangtze River Urban Architectural Design Co. Ltd., 328 Hongwu Road, Nanjing 210000, China \\ Correspondence should be addressed to Zhongfan Chen; 101003944@seu.edu.cn
}

Received 8 January 2018; Revised 26 March 2018; Accepted 2 April 2018; Published 26 April 2018

Academic Editor: Andres Sotelo

Copyright (c) 2018 Xiaopeng Gao et al. This is an open access article distributed under the Creative Commons Attribution License, which permits unrestricted use, distribution, and reproduction in any medium, provided the original work is properly cited.

\begin{abstract}
An experimental study that investigates the behavior of stone slabs strengthened in fixure with near surface mounted (NSM) technique using screw-thread steels and carbon fiber-reinforced polymer (CFRP) bars is presented. A total of ten full-scale stone slabs were tested under a four-point bending loading to investigate the effect of groove dimension, reinforcement ratios, and reinforcement materials on the flexural performance of stone slabs. The test results included failure characteristics, yield and ultimate capacities, deflection of midspan, and cracking behavior of stone slabs. The test results indicate that with the increase of groove height and groove width, cracking load and middeflection decrease by $6.4 \%-14.18 \%$; however, failure load and middeflection increase by $4.7 \%-41.2 \%$. Cracking load, failure load, and failure displacement of stone slabs adopting NSM screwthread steels increased by $10.9 \%, 167 \%$, and $617 \%$, respectively, under the maximum reinforcement ratios of $0.629 \%$ over the control slab without NSM bars. Meanwhile, with the increase of reinforcement ratios, the failure mode transforms from brittle failure to ductile failure. The calculation results of strength are in agreement with the experimental results. Finally, it can be concluded that NSM CFRP bars are more effective than NSM screw-thread steels to improve flexural capacity with the same reinforcement ratios.
\end{abstract}

\section{Introduction}

The near surface mounted (NSM) bar strengthening technique involves bonding bars into grooves cut into the concrete cover of a structural member to be strengthened. The technique offers many advantages over external bonding of bar reinforcement, for instance, increased bond capacity, due to a larger bonded surface area, and protection from external damage due to external impacts, since the bar is embedded within the concrete cover. Near surface mounted (NSM) screw-thread steels and CFRP bars are now emerging as a promising technique widely used for increasing flexural and shear strength of deficient RC members $[1,2]$ and were extended to unreinforced masonry (URM) walls [3], timber beams [4], and glulam bamboo beams [5] for increasing shear and flexural capacity. The aforementioned research is aimed at the components; for the structures, reinforced concrete frames strengthened with NSM bars were investigated and pointed out that reinforced concrete frames strengthened with NSM bars have a higher ultimate strength. [6].

Meanwhile, the first practical use of NSM screw-thread steels for the strengthening of RC structures dates back to the early 1950s [7], and applications of NSM stainless steel bars for the strengthening of masonry arch bridges have also been presented [8]. Bonding mechanisms and pullout test between concrete structures and NSM FRP were investigated in detail [9-11]; cyclic loading response of RC beams strengthened in shear with GFRP rods using NSM technique was investigated, and an effective finite element method to model the cyclic response of RC beams was developed [12]. Meanwhile, the NSM method was combined with externally bonded reinforcement [13]; a new proposal of T shape CFRP 


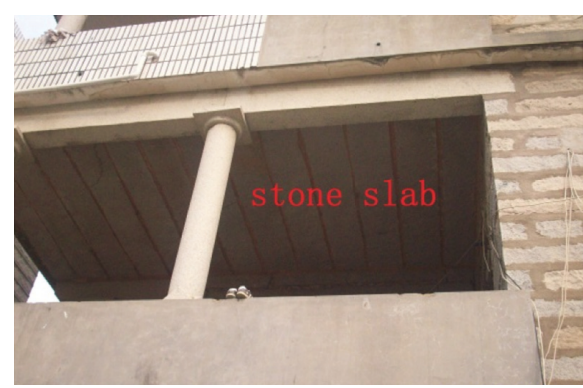

(a)

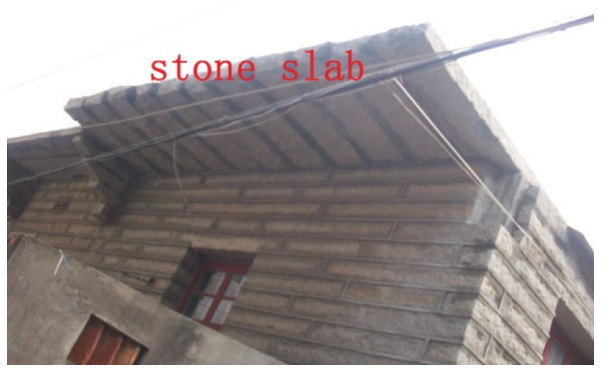

(b)

FIGURE 1: The building floors of stone masonry building.

profile [14] was provided; and ductile strengthening using externally bonded and near surface mounted composite systems was evaluated [15]. Nonlinear finite element modeling of RC beams strengthened with NSM FRP rods [16] was developed to predict the response of RC beams. A comprehensive review of existing research was provided [17-19] in NSM FRP reinforcement NSM prestressed reinforcement and design method [20].

Like concrete, masonry, or other members as quasibrittle material, however, the NSM approach with steels and CFRP bars has rarely been applied to brittle members like granite stone slabs to investigate the flexural behavior. So, it is necessary to study flexural behavior of stone slabs adopting NSM steels and FRP bars and compare their disadvantages and advantages.

Granite stone slabs as building floors are commonly used in Europe and in southeast coastal rural buildings of China (Figure 1). Its excellent performance includes local material, high compressive strength, corrosion resistance, weather ability, and resisting typhoon loading. However, granite stone slabs as a brittle material are easily brittle fracture in shock and vibration, especially in earthquake action; thus, both flexural capacity and ductility are very poor and very easy to cause casualties and property loss. Obviously, flexural capacity of granite stone slabs is primarily controlled by section dimensions and natural defects of stone material. In many countries, building structural seismic design standards [21] and codes [22] prohibits using pure granite stone slabs as bearing members. For improving flexural capacity and ductility of granite stone slabs, NSM screw-thread steels and CFRP bars by grooving on the tension face of stone slabs were adopted to improve flexural capacity.

The main reason of adopting screw-thread steels and CFRP bars is that screw-thread steel bars and CFRP bars can increase bonding area and bonding force to avoid slipping failure and bonding failure. Meanwhile, screw-thread steels and CFRP bars had sufficient embedment length embedded into the stone slab in order to fully utilize their tensile strength.

In this paper, stone slabs strengthened with NSM composite technique and their flexural performance were investigated by making the stone slab subject to a fourpoint bending loading. A total of ten full-scale stone slabs (one control slab, six slabs strengthened with NSM screwthread steels, and three slabs strengthened with CFRP bars) were tested. The study parameters include grooving dimension, reinforcement ratios, and reinforcement materials. Load, deflection, and strain data were analyzed to understand cracking behavior and failure mode of stone slabs. The test results showed that the NSM screw-thread steels and CFRP bars significantly improved the flexural capacity.

\section{Materials and Methods}

In this section, detailed material information was presented including stone material, high-strength epoxy resin, screwthread steels, and CFRP bars. The kind of stone material is quanzhou white granite.

\subsection{Material Properties}

2.1.1. Uniaxial Compressive Strength of Granite Stone Cubic Block. Six specimens in total which are $70 \mathrm{~mm} \times 70 \mathrm{~mm}$ granite cubic blocks are tested in the $2000 \mathrm{kN}$ hydraulic testing machine according to the code for design of masonry structures [23]. The failure mode is shown in Figure 2. The results are shown in Table 1 . The values of uniaxial compressive strength had a certain discretization. The maximum discretization was $39.7 \%$.

2.1.2. Tensile Splitting Strength of Granite Stone Cylinders. A minimum of three cylinders were tested to measure the splitting strength of stone materials [22]. The average value of all samples was adopted. Six specimens in total in which diameter and height were all $50 \mathrm{~mm}$ were tested in the $300 \mathrm{kN}$ hydraulic testing machine according to British Standards Institute [24]. The failure mode is shown in Figure 3. The results are shown in Table 2. The values of tensile splitting strength had a certain discretization. The maximum discretization was $22.4 \%$.

2.1.3. Stress-Strain Curve for Granite Stone Cylinder. Six granite stone cylinders with a dimension of $50 \mathrm{~mm}$ diameter and $100 \mathrm{~mm}$ height were tested in the $2000 \mathrm{kN}$ hydraulic testing machine to obtain the stress-strain curve. The axial direction and transverse direction in the middle of specimen side surface glued separately the electric-resistance strain gauge whose gauge length was $100 \mathrm{~mm}$ to measure axial 


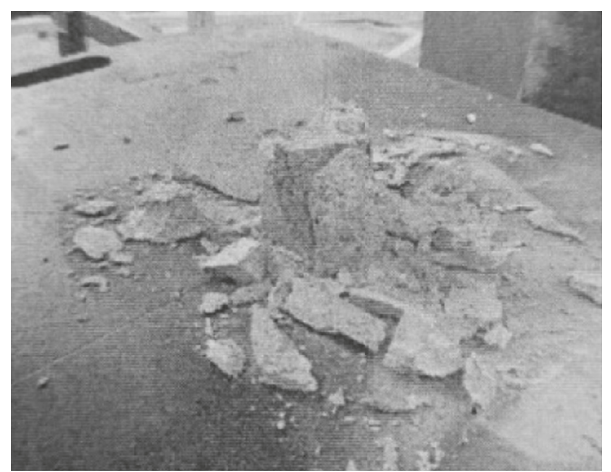

(a)

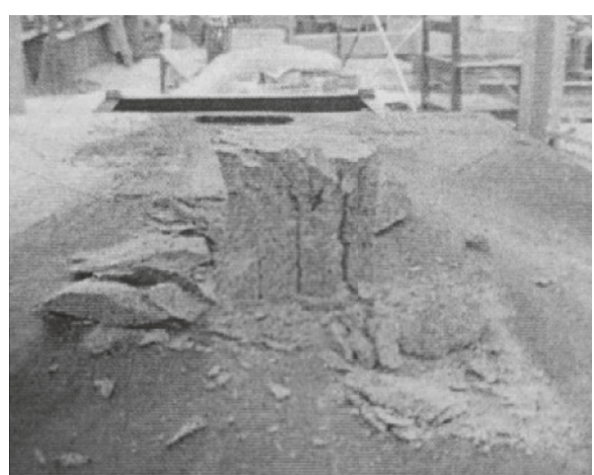

(b)

FIgURE 2: Failure mode of the granite stone cubic block.

TABle 1: Compressive test results.

\begin{tabular}{|c|c|c|c|c|}
\hline Specimen labels & Specimen dimension & Failure load $(\mathrm{kN})$ & Uniaxial compressive strength $(\mathrm{MPa})$ & Average value $(\mathrm{MPa})$ \\
\hline 1 & \multirow{6}{*}{$70 \mathrm{~mm} \times 70 \mathrm{~mm}$} & 742.1 & 155.8 & \multirow{6}{*}{$126.5 \pm 18.7$} \\
\hline 2 & & 556.4 & 113.6 & \\
\hline 3 & & 690.3 & 142.9 & \\
\hline 4 & & 652.2 & 137.0 & \\
\hline 5 & & 559.8 & 115.9 & \\
\hline 6 & & 447.2 & 93.9 & \\
\hline
\end{tabular}

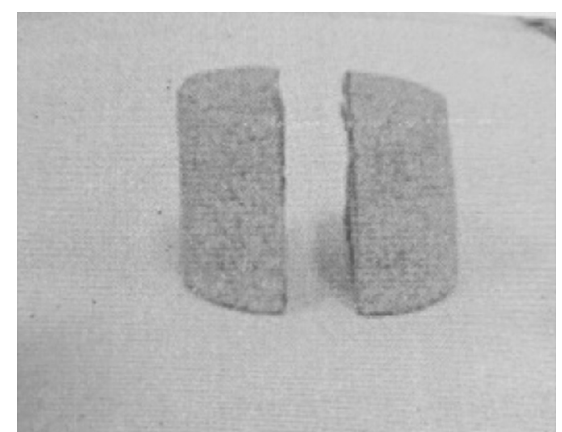

(a)



(b)

Figure 3: Failure mode of tensile splitting test for granite.

TABLE 2: Tensile splitting strength results for granite.

\begin{tabular}{|c|c|c|c|c|}
\hline Number of specimen & Specimen dimensions $(D \times H / \mathrm{mm})$ & Failure loading $(\mathrm{kN})$ & Tensile splitting strength (MPa) & Average value $(\mathrm{MPa})$ \\
\hline 1 & \multirow{6}{*}{$50 \mathrm{~mm} \times 50 \mathrm{~mm}$} & 38.4 & 9.98 & \multirow{6}{*}{$8.94 \pm 0.79$} \\
\hline 2 & & 37.2 & 9.67 & \\
\hline 3 & & 36.7 & 9.54 & \\
\hline 4 & & 31.9 & 8.12 & \\
\hline 5 & & 33.0 & 8.57 & \\
\hline 6 & & 29.8 & 7.74 & \\
\hline
\end{tabular}

strain and transverse strain by $1000 \mathrm{kN}$ force sensor. Test results clarified that only four specimens' data were effective, and the other two specimens were ineffective. The stressstrain curves for the four specimens are displayed in Figure 4 and failure mode is shown in Figure 5.
The modulus of elasticity and Poisson's ratio according to ASTM C469 [25] are shown in Table 3.

All of granite stone cylinders under uniaxial compressive loading followed a linear elastic behavior up to failure (Figure 4) and experienced Poisson's failure (Figure 5). 


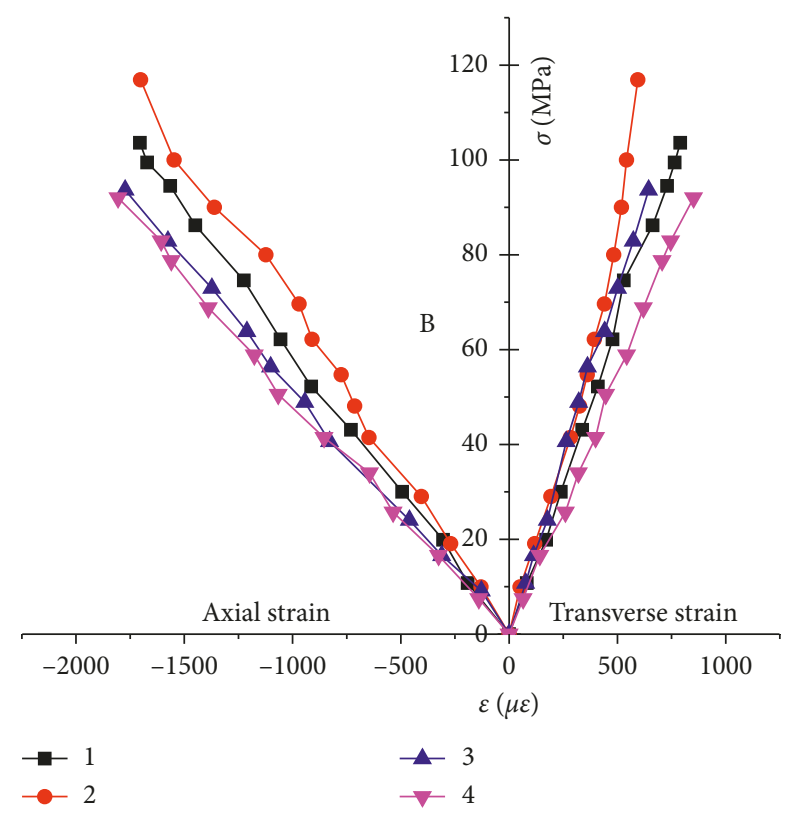

FIGURE 4: Stress-strain curve of the granite stone cylinder.

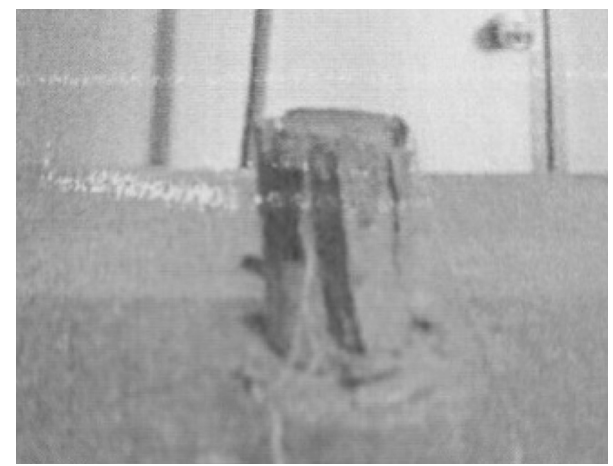

FIgURE 5: Failure mode of the granite stone cylinder.

2.1.4. Properties of High-Strength Epoxy Resin. The strength of high-strength epoxy resin was provided by Nanjing Mankate Science \& Technology Co., Ltd., as shown in Table 4.

2.1.5. Properties of Screw-Thread Steels. Tensile tests of screw-thread steels were performed to determine their engineering properties. High-strength screw-thread steels' strength grade is HRB400 and diameters are, respectively, $6 \mathrm{~mm}$ and $8 \mathrm{~mm}$. Each diameter of screw-thread steels used, respectively, 3 specimens to obtain their properties. The average tensile strength, ultimate strain, and modulus of elasticity were obtained according to ASTM [26]. The results are shown in Table 5. Meanwhile, the stress-strain curves are shown in Figures 6 and 7.

2.1.6. Properties of CFRP Bars. Tensile tests of CFRP bars were carried out to determine their engineering properties and that the CFRP diameter is $6 \mathrm{~mm}$. The average tensile strength, ultimate strain, and modulus of elasticity were obtained from the test result of six specimens according to ASTM [26]. The results are shown in Table 6.

\subsection{Experimental Program}

2.2.1. Specimen Design. The dimensions and reinforcement details of stone slabs are presented in Figure 8 and Table 7. The cross-sectional dimensions of stone slabs were $400 \mathrm{~mm} \times 400 \mathrm{~mm}$, and the length of stone slabs was $3000 \mathrm{~mm}$. The effective span and shear span lengths of the stone slabs were $2700 \mathrm{~mm}$ and $900 \mathrm{~mm}$. The layout of screwthread steels and CFRP bars and location of groove dimensions are shown in Figure 8.

The study parameters mainly included reinforcement ratios, grooving dimension, and reinforcement materials (Figure 8). According to the design method of RC members with NSM FRPS [27], the grooving width $b_{c}=2 \mathrm{D}$ and adhesive protective layer thickness $b_{\mathrm{j}}=0.5 \mathrm{D}$ ( $\mathrm{D}$ is the diameter of CFRP bars and screw-thread steels). Each of the specimens had a groove cut in the tension face and oriented along the longitudinal axis where screw-thread steels and CFRP bars had to be mounted. The parameters of detailed specimens are presented in Table 7.

However, the flexural performance of stone slabs surely depended on the grain of stone; however, the experimental study including uniaxial compressive strength of granite stone cubic block (Table 1), tensile splitting strength of granite stone cylinders (Table 2), and stress-strain relationship (Table 3) indicated that the grain of stone had a little influence on the mechanical properties, so we assumed that the flexural performance was not affected by the grain of stone. Meanwhile, we conducted the experimental study for the point of macroscopic view, not considering the effect of microscopic grain of stone, so we only presented the section photo of the stone slab for CB-2, as shown in Figure 8(j).

2.2.2. Strengthening Procedure. In this section, a new construction method of stone slabs is described as follows. Firstly, on the tension surface of the stone slab, a groove was cut in the correct location. Secondly, the groove is then filled halfway with high-strength epoxy resins, and the screwthread steels or CFRP bars are placed in the groove and lightly pressed to force the paste to flow around the bars. Thirdly, high-strength epoxy resin was filled completely without any space between the bars and the sides of the groove. Finally, the groove was then filled with more highstrength epoxy resin and the surface was leveled. The detailed fabricating flowchart is shown in Figure 9.

2.2.3. Test Device. The load was generated with a $5000 \mathrm{kN}$ compression testing machine and was transferred to the stone slab by means of a steel beam supported by two rollers, which applied loading along two lines spaced at $900 \mathrm{~mm}$. The stone slabs were tested under four-point bending (Figure 10).

The flexural performance of stone slab NSM screwthread steels and CFRP bars was investigated. The main contents included cracking strength, cracking position, 
TABLE 3: Uniaxial compressive test results.

\begin{tabular}{lcccccc}
\hline $\begin{array}{l}\text { Specimen } \\
\text { labels }\end{array}$ & $\begin{array}{c}\text { Specimen dimension } \\
D \times H / \mathrm{mm}\end{array}$ & $\begin{array}{c}\text { Ultimate compressive } \\
\text { strength }(\mathrm{kN})\end{array}$ & $\begin{array}{c}\text { Elastic modulus } \\
(\mathrm{GPa})\end{array}$ & $\begin{array}{c}\text { Poisson's ratio } \\
(\mathrm{MPa})\end{array}$ & $\begin{array}{c}\text { Axial peak } \\
\text { strain }(\mu \varepsilon)\end{array}$ & $\begin{array}{c}\text { Transverse peak } \\
\text { strain }(\mu \varepsilon)\end{array}$ \\
\hline 1 & & 92.0 & 50.0 & 0.45 & 1806 & -852 \\
2 & & 103.6 & 58.3 & 0.45 & 1705 & -790 \\
3 & $50 \mathrm{~mm} \times 100 \mathrm{~mm}$ & 93.7 & 53.0 & 0.36 & 1773 & -644 \\
4 & & 116.9 & 63.9 & 0.34 & 1702 & -594 \\
Mean value & & $101.6 \pm 8.7$ & $56.3 \pm 4.8$ & $0.40 \pm 0.05$ & $1747 \pm 43$ & $-720 \pm 101$ \\
\hline
\end{tabular}

Table 4: Properties of high-strength epoxy resin.

\begin{tabular}{lcccc}
\hline \multirow{2}{*}{ Strength name } & \multicolumn{2}{c}{ Technical indexes } & \multirow{2}{*}{ Test result } & \multirow{2}{*}{ Single Assessment } \\
& A grade adhesive & B grade adhesive & $>7.5$ & 17.7 \\
Splitting tensile strength $(\mathrm{MPa})$ & $>8.5$ & $>40$ & 61.7 & A grade \\
Flexural strength $(\mathrm{MPa})$ & $>50$ & $>60$ & 92.9 & A grade \\
Compressive strength $(\mathrm{MPa})$ & $>60$ & Sampling preparation ratio A: B $=2: 1(\mathrm{~W} / \mathrm{W})$ & A grade \\
Remarks & & & \\
\hline
\end{tabular}

TABle 5: Properties of screw-thread steels.

\begin{tabular}{lcccc}
\hline Label of specimen & Yield strength $(\mathrm{MPa})$ & Ultimate strength $(\mathrm{MPa})$ & Yield strain $(\mu \varepsilon)$ & Elastic modulus $(\mathrm{MPa})$ \\
\hline $6-1$ & 460 & 657 & 2289 & 2303 \\
$6-2$ & 463 & 651 & 2254 & $2.01 \times 10^{5}$ \\
$6-3$ & 453 & 638 & $2282 \pm 18.7$ & $2.01 \times 10^{5}$ \\
Average value of $6 \mathrm{~mm}$ & $459 \pm 3.7$ & $649 \pm 7$ & 2274 & $2.01 \times 10^{5}$ \\
$8-1$ & 457 & 654 & 2179 & $2.01 \times 10^{5}$ \\
$8-2$ & 438 & 633 & 2229 & $2.01 \times 10^{5}$ \\
$8-3$ & 448 & 651 & $2227 \pm 32.3$ & $2.01 \times 10^{5}$ \\
Average value of $8 \mathrm{~mm}$ & $448 \pm 6.3$ & $646 \pm 8.7$ & $2.01 \times 10^{5}$ \\
\hline
\end{tabular}



FIGURE 6: Stress-strain curves of $6 \mathrm{~mm}$ screw-thread steels.

ultimate loading, midspan deflection, screw-thread steels' strain, CFRP bars' strain, stone slab's strain, and joint work characteristic.

When stone slabs satisfied one of the following criteria including crush of stone slab, too large deflection deformation, fracture of screw-thread steels and CFRP bars,

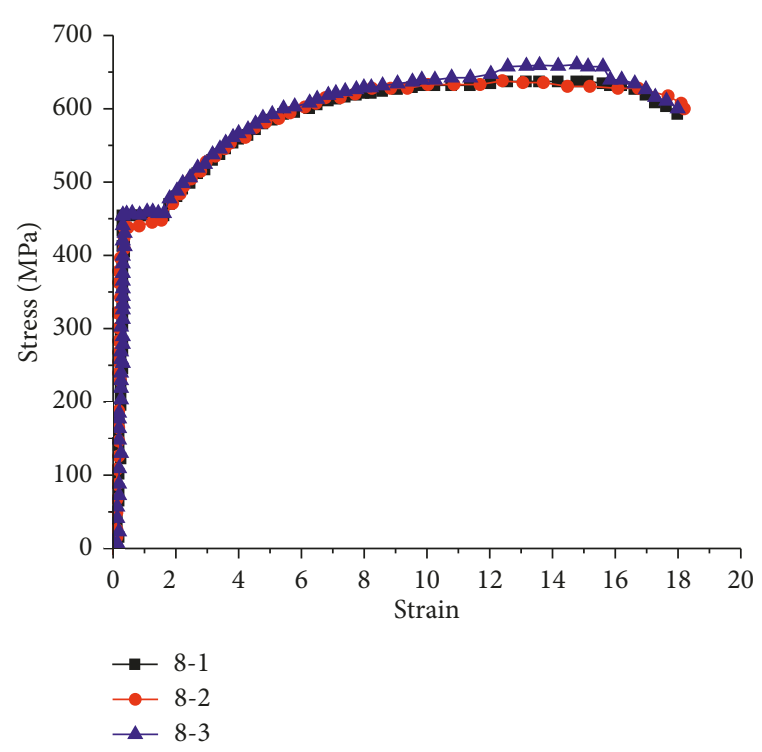

FIGURE 7: Stress-strain curves of $8 \mathrm{~mm}$ screw-thread steels.

and rapidly descending capacity, the stone slabs were considered as failure, terminating the experiment.

An initial low-static load was performed in every stone slab to verify that both the mechanical equipment and electronic equipment were working properly. 
TABle 6: Properties of CFRP bars.

\begin{tabular}{lccc}
\hline Specimen & Ultimate strength $(\mathrm{MPa})$ & Ultimate tensile strain $(\mu \varepsilon)$ & Elastic modulus $(\mathrm{GPa})$ \\
\hline 1 & 2326 & 16400 & 143 \\
2 & 2314 & 16000 & 144 \\
3 & 2240 & 16300 & 147 \\
4 & 2156 & 14900 & 146 \\
5 & 2272 & 15100 & 149 \\
6 & 2264 & 15500 & 147 \\
Average value & $2262 \pm 42.67$ & $15700 \pm 533.33$ & $146 \pm 1.67$ \\
\hline
\end{tabular}

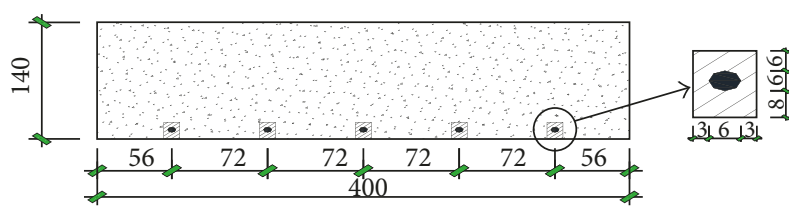

(a)

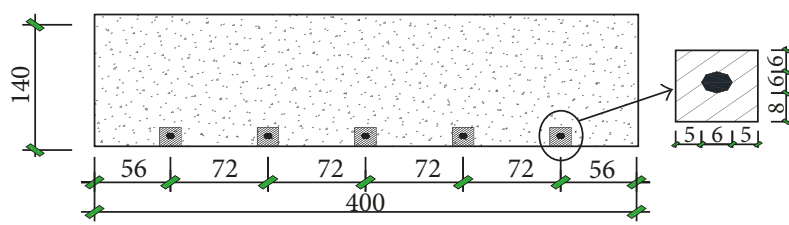

(c)

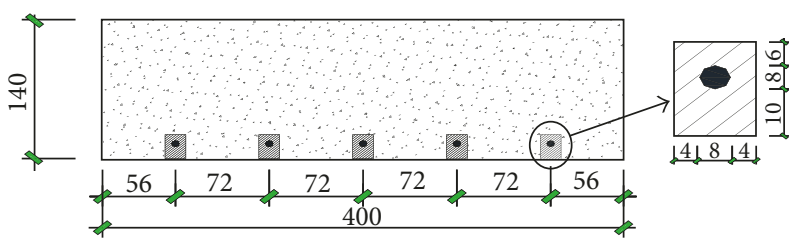

(e)

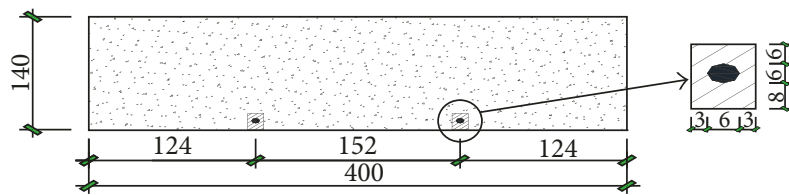

(g)

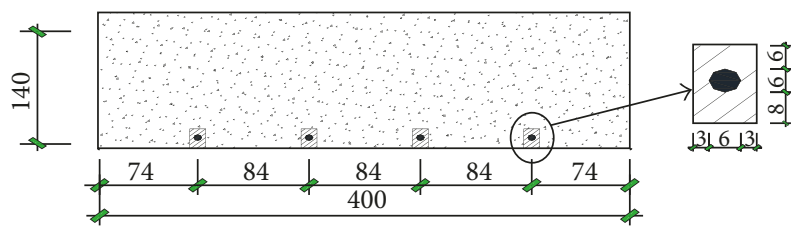

(i)

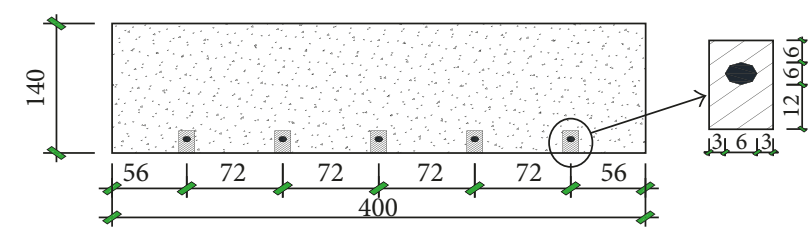

(b)

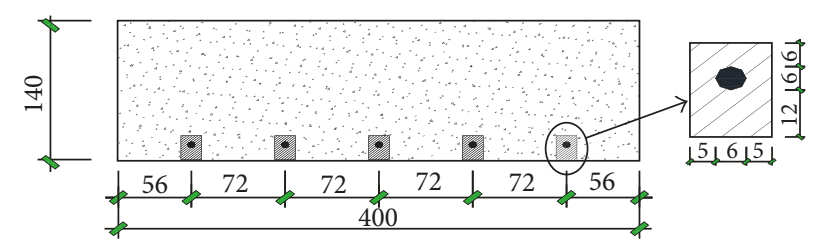

(d)

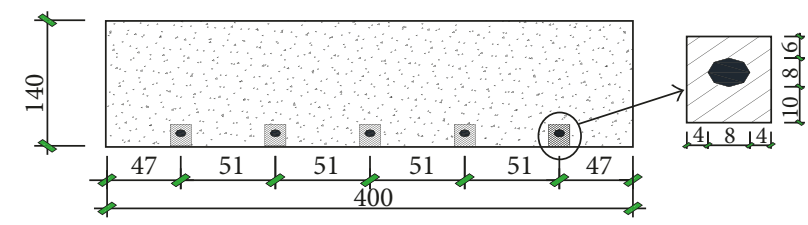

(f)

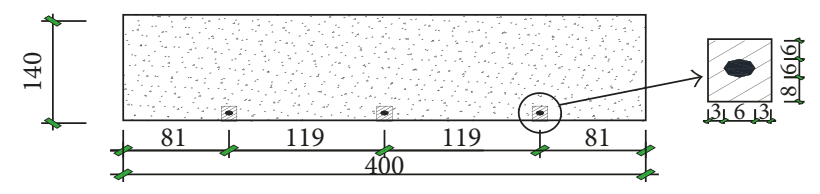

(h)

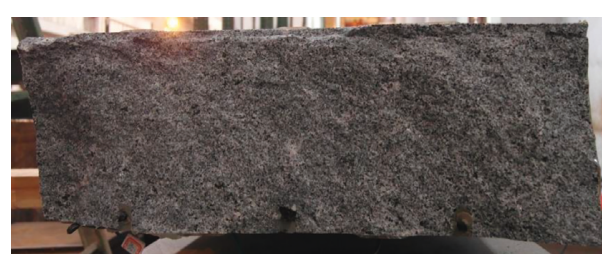

(j)

Figure 8: Dimensions of stone slab specimens: (a) GB-1; (b) GB-2; (c) GB-3; (d) GB-4; (e) GB-5; (f) GB-6; (g) CB-1; (h) CB-2; (i) CB-3; (j) section photo of CB-2.

2.2.4. Test Setup. Each stone slab was instrumented with three linear variable differential transducers (LVDTs). One LVDT was placed at the midspan to measure midspan deflection of the stone slab; the other two were used to measure slip of bars at the end of stone slabs. The detailed arrangements are shown in Figure 11.
2.2.5. Strain Gauge Layout of Screw-Thread Steels and CFRP Bars. Strain gauges were used in the screw-thread steels and CFRP bars to record their strains at different levels of loads. Each bar was arranged with three strain gauges which are located in the midspan and loading point of the stone slab. The detailed arrangements are presented in Figure 12. 
TABLe 7: Specimen details.

\begin{tabular}{lccccc}
\hline $\begin{array}{l}\text { Specimen } \\
\text { label }\end{array}$ & $\begin{array}{c}\text { Net span } \\
(\mathrm{mm})\end{array}$ & $\begin{array}{c}\text { Groove dimension width } \times \text { height } \\
\left(\mathrm{mm}^{2}\right)\end{array}$ & $\begin{array}{c}\text { Material } \\
\text { specification }\end{array}$ & $\begin{array}{c}\text { Groove spacing } \\
(\mathrm{mm})\end{array}$ & $\begin{array}{c}\text { Reinforcement } \\
\text { ratios }\end{array}$ \\
\hline B-1 & 2700 & 0 & 0 & 0 & 0 \\
GB-1 & 2700 & $12 \times 20$ & 5 C6 & 60 & $0.254 \%$ \\
GB-2 & 2700 & $12 \times 24$ & 5 C6 & 60 & $0.254 \%$ \\
GB-3 & 2700 & $16 \times 20$ & 5 C6 & 56 & $0.254 \%$ \\
GB-4 & 2700 & $16 \times 24$ & 5 C6 & 56 & $0.254 \%$ \\
GB-5 & 2700 & $16 \times 24$ & 5 C8 & 56 & $0.449 \%$ \\
GB-6 & 2700 & $16 \times 24$ & 7 C 8 & 35 & $0.629 \%$ \\
CB-1 & 2700 & $12 \times 20$ & 2 A6 & 140 & $0.101 \%$ \\
CB-2 & 2700 & $12 \times 20$ & 3 A6 & 95 & $0.151 \%$ \\
CB-3 & 2700 & $12 \times 20$ & 4 A6 & 72 & $0.202 \%$ \\
\hline
\end{tabular}

Note. GB-1-6: NSM screw-thread steels; CB-1-3: NSM CFRP bars.

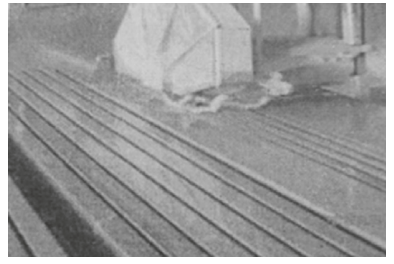

(a)



(b)

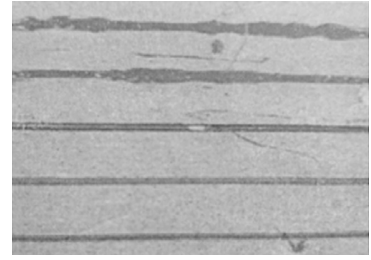

(c)

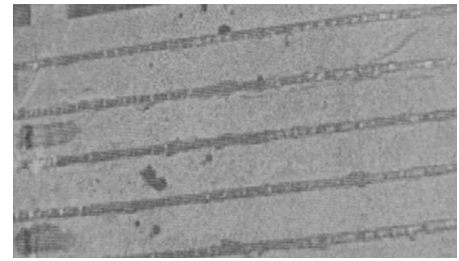

(d)

FIGURE 9: Flowchart of stone slab NSM bar installation: (a) grooving; (b) injecting demicolpus adhesive; (c) reinforcing; (d) full injection and curing.

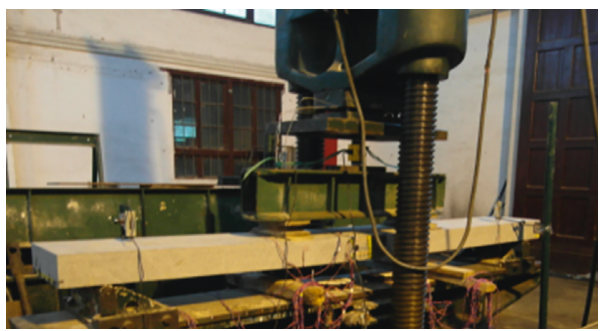

(a)

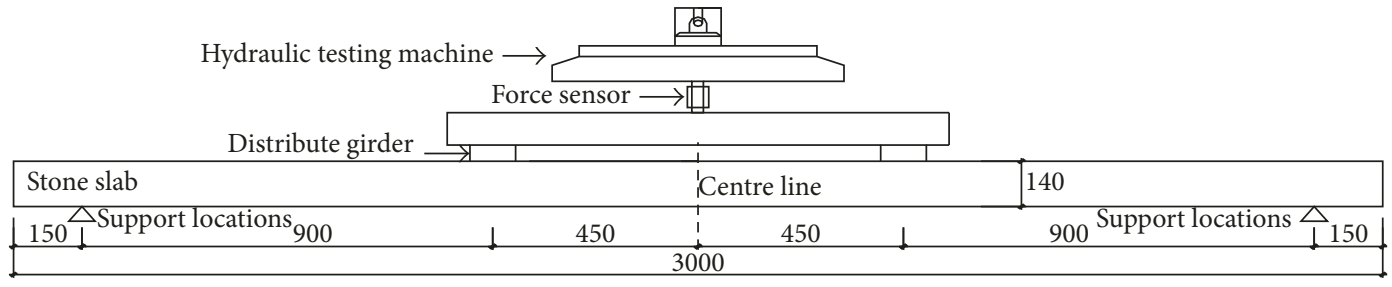

(b)

FIGURE 10: Test loading equipment: (a) test equipment and (b) loading sketch (mm).

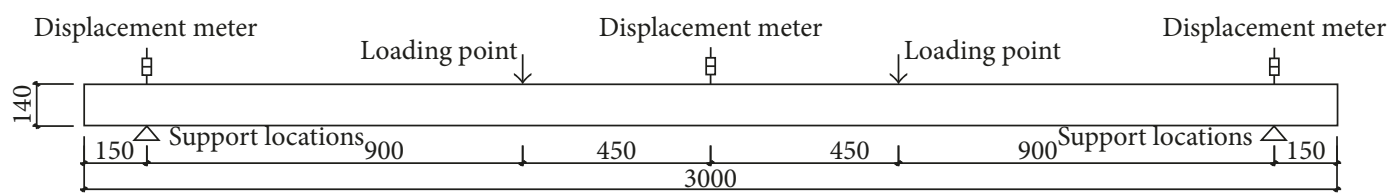

Figure 11: Arrangement of displacement transducer (mm). 


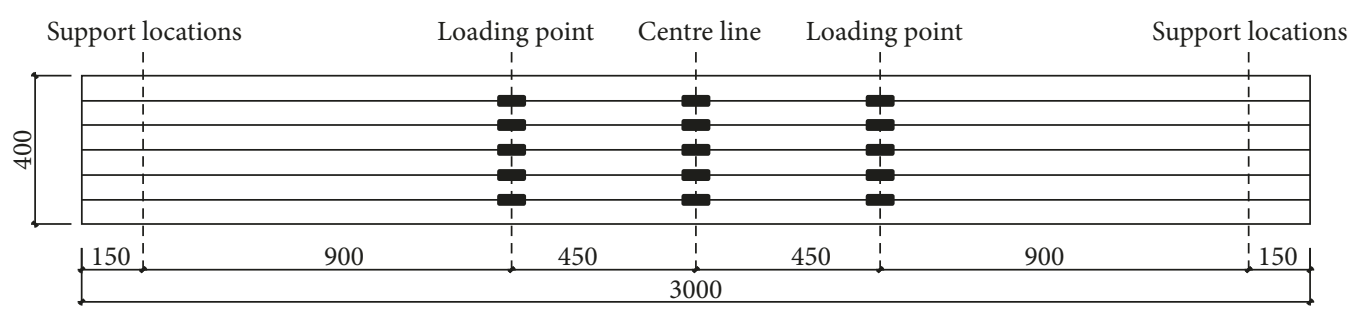

FIGURE 12: Strain gauge layout of screw-thread steels and CFRP bars (mm).

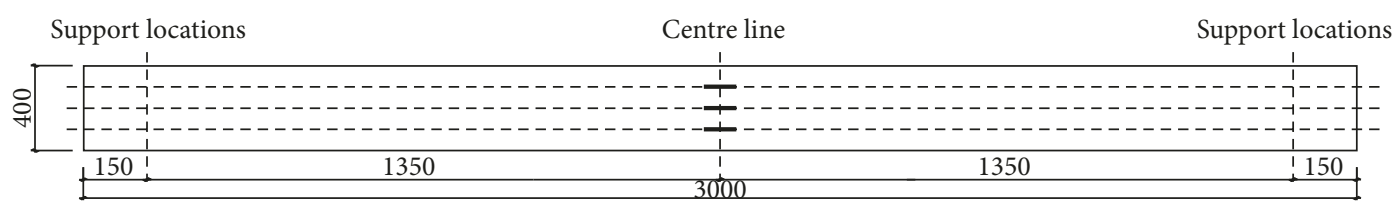

(a)

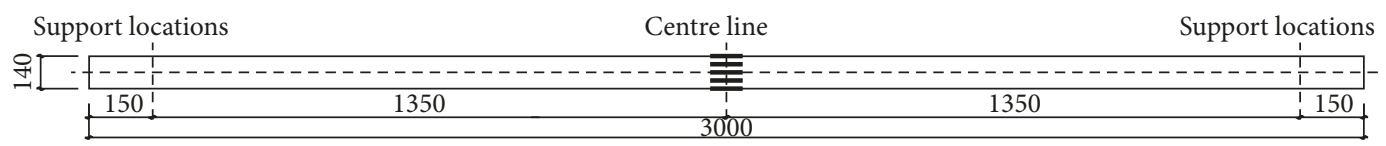

(b)

FIGURE 13: Strain arrangement of the stone slab: (a) slab bottom (top) (mm) and (b) slab side (mm).

2.2.6. Strain Gauge Layout of Stone Slab. Three strain gauges were arranged at the bottom of the slab to measure tensile strain in the tension zone; three strain gauges at the top of the slab to measure compressive strain in the compressive zone; and five strain gauges along cross section's height in the midspan of the stone slab to measure variation law of strain. The details are shown in Figure 13.

\section{Results}

In Section 2.1.3, as is known, the failure mode of stone material is brittle failure. For the flexural stone slab, the stone slab cracks when its tensile stress exceeds the limiting tensile strength of stone materials; the crack formation and propagation in stone slabs depend on the tensile strength; once the stone slab cracks, it fails. Flexural cracks are present in the vertical stone slab surface direction. Crack formation process is similar to concrete members [21-29]. The following section presents the detailed failure progress and failure mode.

\subsection{Failure Process and Failure Mode of Granite Stone Slab Adopting NSM Screw-Thread Steels and CFRP Bars}

3.1.1. Specimen B-1 (Control Slab). In the process of loading, the flexural crack suddenly formed at a load of $24.18 \mathrm{kN}$ with a "bang" noise. The flexural crack was regular and perpendicular to the slab surface and located in $100 \mathrm{~mm}$ away from the midspan. This indicated that the failure mode of the pure stone slab is brittle failure. The failure mode and crack location of B-1 are given in Figures 14 and 15.

3.1.2. Specimen $G B-1$. The first vertical crack whose location is $170 \mathrm{~mm}$ away from the midspan formed at a load of $30.17 \mathrm{kN}$ (Figure 16). This corresponded to an increase in the

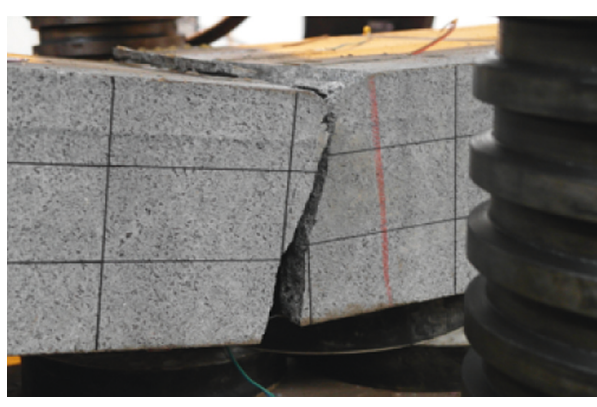

FIgURE 14: Failure mode of B-1.

cracking capacity of $27 \%$ over the control slab. Meanwhile, the midspan deflection is $5.05 \mathrm{~mm}$, and the tensile strain of midspan bottom of the slab was $308 \mu \varepsilon$. Average strain of steel bars was $398 \mu \varepsilon$. After cracking, the bearing capacity of the stone slab descended to $13.47 \mathrm{kN}$. When the crack was stable, loading was continued. When the crack almost fully passed through the cross section, the loading started descending. When the loading descended to $13.29 \mathrm{kN}$, the stone slab was separated in two parts in the location of the first vertical crack with a "bang" noise. Eventually failure occurred by splitting the stone slab into two parts, and screw-thread steels were crushed. At this time, the middeflection was $12.16 \mathrm{~mm}$, and tensile strain of midspan bottom of the slab was $296 \mu \varepsilon$. The failure mode is shown in Figure 17. Debonding failure happened between screwthread steels and stone slabs (Figure 17(c)). Finally, slip displacements of five steel bars, respectively, produced a slip of $4 \mathrm{~mm}, 5 \mathrm{~mm}, 2 \mathrm{~mm}, 1 \mathrm{~mm}$, and $8 \mathrm{~mm}$.

3.1.3. Specimen GB-2. The only difference between GB-2 and GB-1 is groove height (Table 7). The first vertical crack whose 


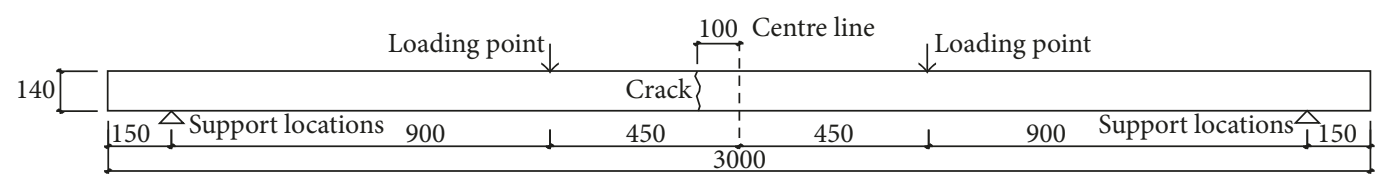

FIGURE 15: Cracking location (mm).

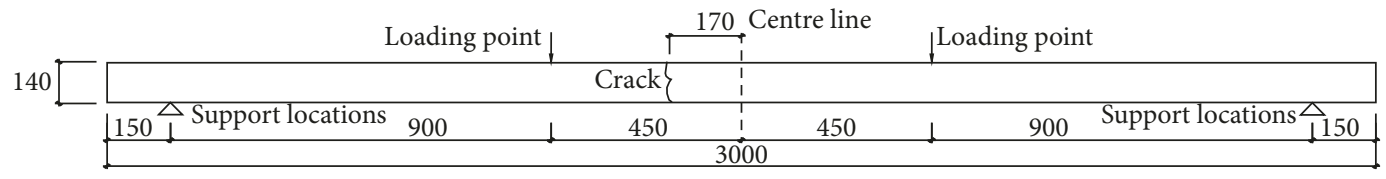

FIGURE 16: Crack location (mm).



(a)



(b)

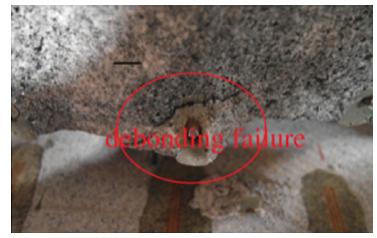

(c)

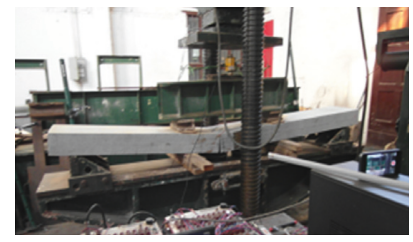

(d)

FIgURE 17: Failure mode of GB-1: (a) initial vertical crack; (b) fully crack; (c) steel bars crushed; (d) failure mode.

\begin{tabular}{|c|c|c|c|c|c|}
\hline \multirow{3}{*}{140} & Loading point & 370 & Centre line & $\downarrow^{\text {Loading po }}$ & \\
\hline & & Crack & 1 & & \\
\hline & $150 \widehat{\jmath}$ Support locations 900 & 450 & 450 & 900 & Support locations $\widehat{\perp} 150$ \\
\hline
\end{tabular}

FIgure 18: Crack location of GB-2 (mm).

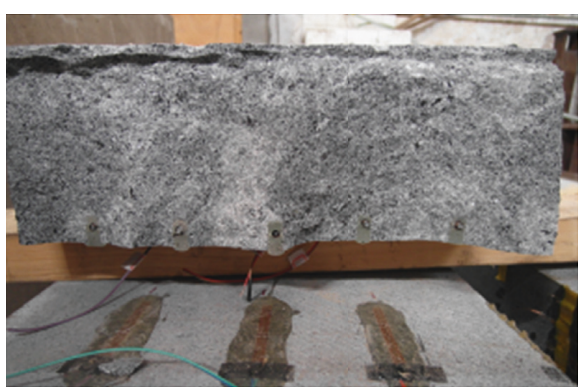

(a)



(b)

Figure 19: Failure mode of GB-2.

location is $370 \mathrm{~mm}$ away from the midspan formed at a load of $28.74 \mathrm{kN}$ (Figure 18). The cracking load was $28.74 \mathrm{kN}$ corresponding to an increase in the cracking capacity of $18.9 \%$ over the control slab and a decrease of $6.4 \%$ over GB- 1 . The crack midspan deflection was $4.63 \mathrm{~mm}$ corresponding to a decrease in the deflection of $8.3 \%$ over GB-1. Tensile strain of midspan bottom of the slab was $440 \mu \varepsilon$ corresponding to an increase in the capacity of $42.9 \%$ over GB-1. The failure load of the stone slab was $19.59 \mathrm{kN}$ corresponding to an increase in the capacity of $4.7 \%$ over GB-1. The failure midspan deflection was $16.72 \mathrm{~mm}$ corresponding to an increase in the deflection of $37.5 \%$ over GB-1. Tensile strain of midspan bottom of the slab was $310 \mu \varepsilon$ corresponding to an increase in the deflection of $4.7 \%$ over GB-1. The average tensile strain of the steel bars was $286 \mu \varepsilon$ corresponding to an increase of $11.7 \%$ over GB-1. At the same time, the stone slab end's side steel bars, respectively, had the slip displacements of $12 \mathrm{~mm}$ and $16 \mathrm{~mm}$. The failure mode of GB-2 is shown in Figure 19, and the crack location is given in Figure 18. Debonding failure happened between screw-thread steels and stone slabs (Figure 19).

3.1.4. Specimen GB-3. The only difference between GB-3 and GB-1 is groove width (Table 7). The cracking load was 


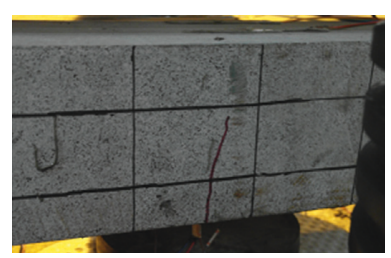

(a)

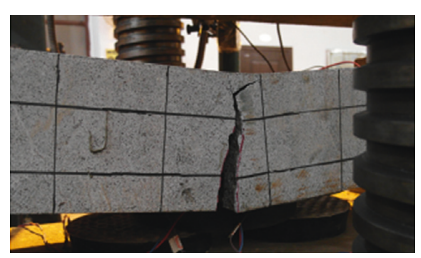

(b)

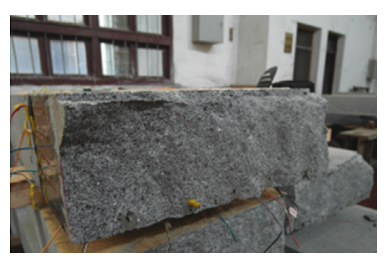

(c)

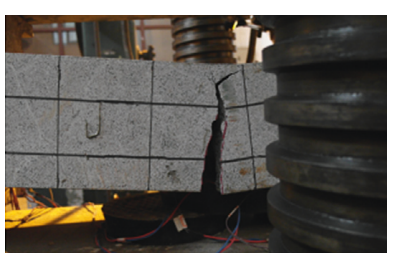

(d)

Figure 20: Failure mode of GB-3: (a) initial vertical crack; (b) fully crack; (c) steel bars; (d) final failure mode.

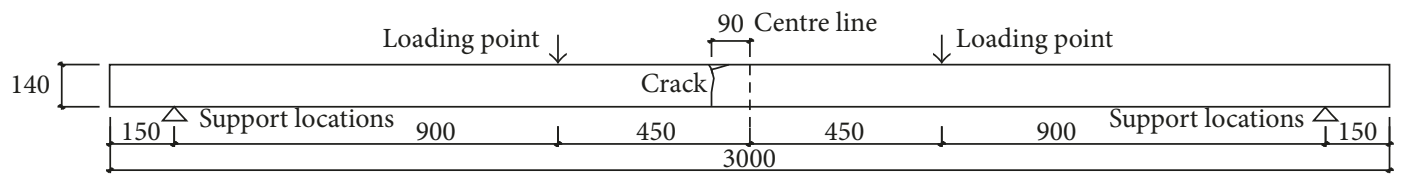

Figure 21: Crack location (mm).

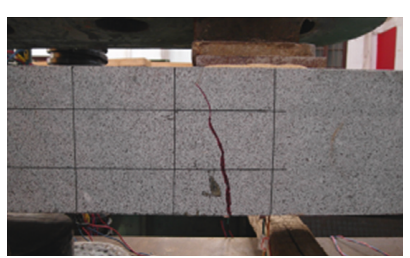

(a)



(b)

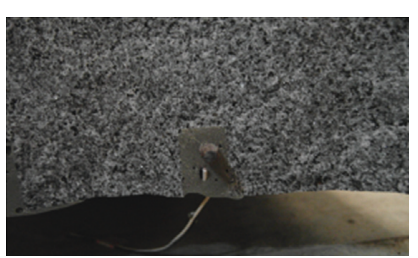

(c)

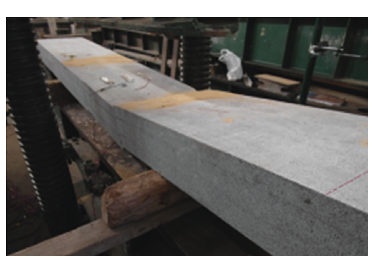

(d)

FIGURE 22: Failure mode of GB-4: (a) initial vertical crack; (b) fully cracking; (c) steel bars crushed; (d) final failure mode.

$28.15 \mathrm{kN}$ corresponding to an increase in the capacity of $16.4 \%$ over the control slab and a decrease of $8.3 \%$ over GB-1. The cracking midspan deflection was $4.3 \mathrm{~mm}$ corresponding to a decrease in the deflection of $14.8 \%$ over GB-1. Tensile strain of midspan bottom of the slab was $373 \mu \varepsilon$ corresponding to an increase in the strain of $21.1 \%$ over GB-1. The failure load of the stone slab was $15.96 \mathrm{kN}$ corresponding to an increase in the capacity of $20 \%$ over GB- 1 . The failure midspan deflection is $17.17 \mathrm{~mm}$ corresponding to an increase in the deflection of $41.2 \%$ over GB-1. Tensile strain of failure of midspan bottom of the slab was $227 \mu \varepsilon$ corresponding to a decrease in the strain of $23.3 \%$ over GB-1. Average tensile strain of steel bars outside the cracks was $238 \mu \varepsilon$ corresponding to a decrease in the strain of $7.6 \%$ over GB-1. At last, the end of five steel bars, respectively, produced a slip of about $1 \mathrm{~mm}, 3 \mathrm{~mm}, 2 \mathrm{~mm}, 6 \mathrm{~mm}$, and $1 \mathrm{~mm}$. The failure mode of GB-3 is shown in Figure 20, and the crack location is shown in Figure 21.

3.1.5. Specimen GB-4. The difference between GB-4 and GB-1 is groove width and height (Table 7). GB-4 is also used to compare the effect of reinforcement ratios with GB-5 and GB-6 in the next section. The cracking load was $33.94 \mathrm{kN}$ corresponding to an increase in the capacity of $40.4 \%$ over the control slab B-1 and an increase of $10.5 \%$ over GB- 1 . The cracking midspan deflection was $5.01 \mathrm{~mm}$ corresponding to a decrease in the deflection of $0.8 \%$ over GB-1. Tensile strain of midspan bottom of the slab was $517 \mu \varepsilon$ corresponding to an increase in the strain of $67.9 \%$ over GB-1. The failure load of the stone slab was $21.09 \mathrm{kN}$ corresponding to an increase in capacity of $58.7 \%$ over GB-1. The failure midspan deflection is $24.34 \mathrm{~mm}$ corresponding to an increase in the deflection of $100.2 \%$ over GB-1. Failure tensile strain of midspan bottom of the slab was $241 \mu \varepsilon$ corresponding to a decrease in the capacity of $18.6 \%$ over GB-1. Average tensile strain of steel bars outside cracks was $817 \mu \varepsilon$ corresponding to an increase in the strain of $219.1 \%$ over GB- 1 . At last, the end of five steel bars, respectively, produced a slip of $4 \mathrm{~mm}, 3 \mathrm{~mm}, 3 \mathrm{~mm}, 2 \mathrm{~mm}$, and $2 \mathrm{~mm}$. The failure mode of GB-4 is shown in Figure 22, and the crack location is shown in Figure 23.

3.1.6. Specimen GB-5. The difference between GB-5 and GB-4 is the reinforcement ratio (Table 7). The cracking load was $34.76 \mathrm{kN}$ corresponding to an increase in the capacity of $2.4 \%$ over GB- 4 and $43.8 \%$ over B-1. The cracking midspan deflection was $5.39 \mathrm{~mm}$ corresponding to an increase in the deflection of $7.6 \%$ over GB-4. Tensile strain of midspan bottom of the slab was $459 \mu \varepsilon$ corresponding to a decrease in the strain of $11.2 \%$ over GB- 4 . The failure load of the stone slab was $38.74 \mathrm{kN}$ corresponding to an increase in the capacity of $83.7 \%$ over GB-4. The failure midspan deflection is $122.5 \mathrm{~mm}$ corresponding to an increase in the deflection of $403.3 \%$ over GB-4. Tensile strain of midspan bottom of the slab was $363 \mu \varepsilon$ corresponding to an increase in the deflection of $50.6 \%$ over GB- 4 . The average tensile strain of 


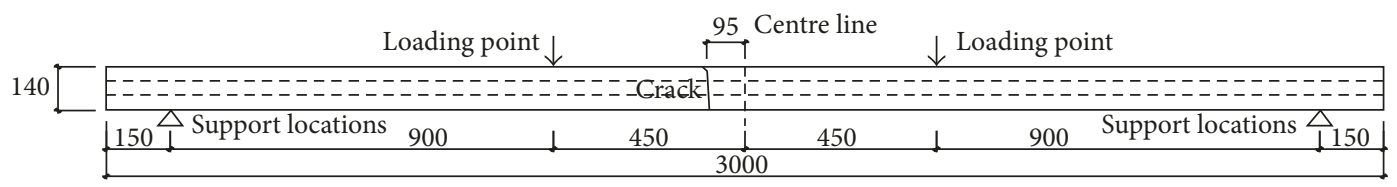

Figure 23: Crack location (mm).

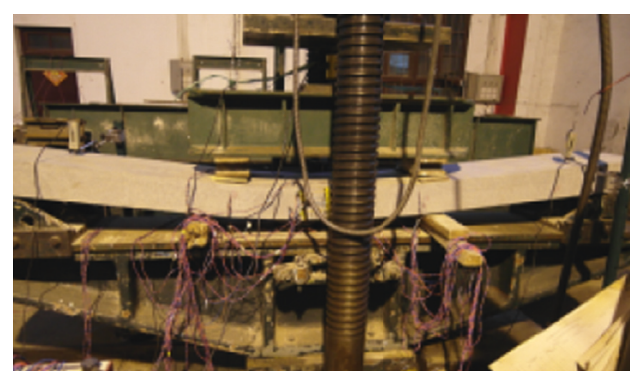

(a)

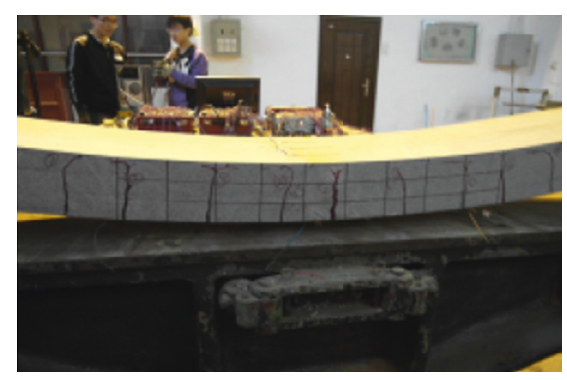

(b)

FIgURe 24: Failure mode of GB-5.



FIgURE 25: Cracking location (mm).

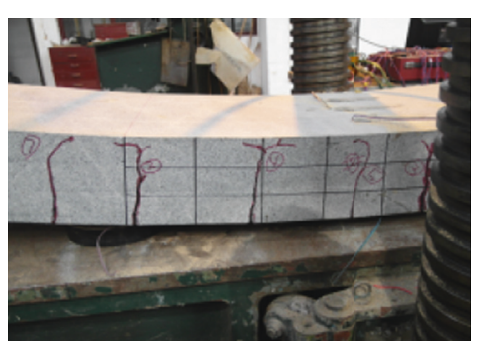

(a)

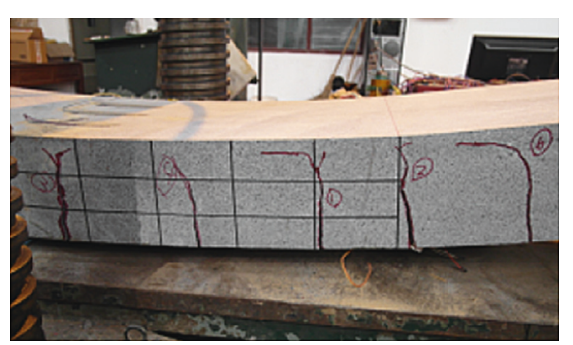

(b)

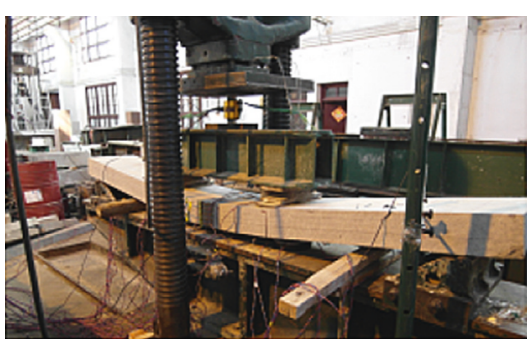

(c)

FIGURE 26: Failure mode of GB-6.

steel bars was $1039 \mu \varepsilon$ corresponding to a decrease in the strain of $27.2 \%$ over GB-4. The end of five steel bars does not have any slip. The failure mode of GB-5 is shown in Figure 24 , and the crack location is shown in Figure 25. The failure mode is similar to the reinforcement concrete beams' failure mode in bending with GFRPS [29] or CFRPS [30]. The failure mode is ductile failure.

3.1.7. Specimen GB-6. The difference between GB-6 and GB4 is reinforcement ratios (Table 7 ). The cracking load was $37.65 \mathrm{kN}$ corresponding to an increase in the capacity of $10.9 \%$ over GB- $4,8.3 \%$ over GB-5, and $55.7 \%$ over B- 1 . The crack midspan deflection was $5.32 \mathrm{~mm}$ corresponding to an increase in the deflection of $6.2 \%$ over GB-4. Tensile strain of midspan bottom of stone slabs was $616 \mu \varepsilon$ corresponding to an increase in the strain of $19.1 \%$ over GB- 4 . The failure load of the stone slab was $56.36 \mathrm{kN}$ corresponding to an increase in the load of $167.2 \%$ over GB-4. The failure midspan deflection is $174.5 \mathrm{~mm}$ corresponding to an increase in the deflection of $616.9 \%$ over GB-4. The end of five steel bars has no slip. GB-6 fracture process is shown in Figure 26, and the location of crack appearance is shown in Figure 27. From the crack location, symmetric distribution was presented. The failure mode is similar to reinforcement concrete beams' failure mode in bending with GFRPS [30] or CFRPS [30]. The failure mode is ductile failure.

3.1.8. Specimen CB-1. CB-1 was strengthened with NSM CFRP bars and used as a control slab to compare the effect of CRP reinforcement ratios with $\mathrm{CB}-2$ and $\mathrm{CB}-3$ in the next 


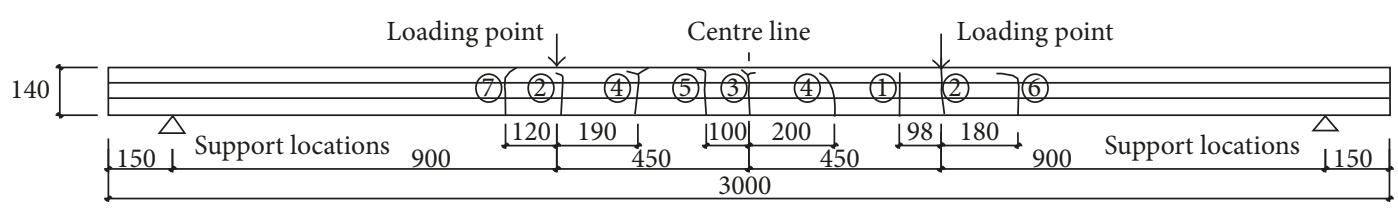

FIgURE 27: Cracking location (mm).



(a)

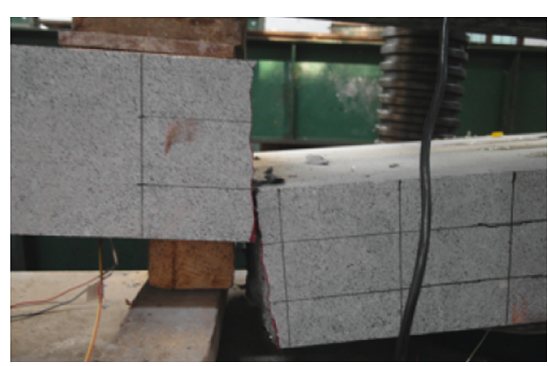

(b)

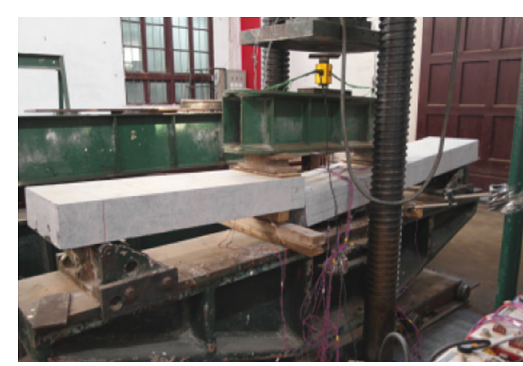

(c)

Figure 28: Failure mode of CB-1.

\begin{tabular}{|c|c|c|c|c|c|}
\hline \multirow{3}{*}{$140 \longleftarrow$} & Loading point $\downarrow$ & & Centre line & $\downarrow^{\text {Loading point }}$ & \\
\hline & & Crack & & & \\
\hline & $150 \triangle$ Support locations 900 & $\begin{array}{l}350 \\
\end{array}$ & 450 & 900 & Support locations $\triangle 150$ \\
\hline
\end{tabular}

FIgURE 29: Cracking location.

section. The first vertical crack whose location is $96 \mathrm{~mm}$ away from the midspan formed at a load of $24.68 \mathrm{kN}$. At the moment, the midspan deflection is $5.5 \mathrm{~mm}$. Tensile strain of midspan bottom of the slab was $352 \mu \varepsilon$. Average strain of the CFRP rod was $291 \mu \varepsilon$. After cracking, the bearing capacity of the stone slab descended to $4 \mathrm{kN}$. When the crack was stable, loading was continued. The crack almost fully passed through the cross section. Then the loading started descending. When the load increased to $12.75 \mathrm{kN}$, the stone slab was separated into two parts in the location of the first vertical crack with a "bang" noise. Eventually failure occurred by splitting the stone slab into two parts. At this time, the middeflection was $14.2 \mathrm{~mm}$. Tensile strain of midspan bottom of the slab was $222 \mu \varepsilon$. At last, the end of two CFRP bars, respectively, produced a slip of $3 \mathrm{~mm}$ and $4 \mathrm{~mm}$. The failure mode of CB-1 is shown in Figure 28, and the crack location is shown in Figure 29.

3.1.9. Specimen CB-2. The difference between CB-2 and CB-1 is the reinforcement ratios (Table 7). The cracking load was $30.09 \mathrm{kN}$ corresponding to an increase in the capacity of $21.9 \%$ over CB-1. The cracking midspan deflection was $5.2 \mathrm{~mm}$ corresponding to a decrease in the capacity of $5.4 \%$ over GB-4. Tensile strain of midspan bottom of the slab was $344 \mu \varepsilon$ corresponding to a decrease in the strain of $2.3 \%$ over CB-1. The failure load of the stone slab was $32.85 \mathrm{kN}$ corresponding to an increase in the capacity of $157.6 \%$ over CB-1. The midspan deflection of failure is $30.65 \mathrm{~mm}$ corresponding to an increase in the capacity of $115.8 \%$ over CB-1.
Two of three CFRP rods have slip about, respectively, $5 \mathrm{~mm}$ and $3 \mathrm{~mm}$. The failure mode of CB-2 is shown in Figure 30, and the cracking location is shown in Figure 31.

3.1.10. Specimen CB-3. The difference between CB-3 and CB-1 is the reinforcement ratios (Table 7). The cracking load was $28.35 \mathrm{kN}$ corresponding to an increase in the capacity of $14.8 \%$ over CB-1 and a decrease of $5.8 \%$ over CB-2. The cracking midspan deflection was $5.68 \mathrm{~mm}$ corresponding to an increase in the deflection of $3.3 \%$ over CB-1 and an increase in the capacity of $9.2 \%$ over CB-2. Tensile strain of midspan bottom of the slab was $675 \mu \varepsilon$ corresponding to an increase in the strain of $91.8 \%$ over CB-1 and an increase in the strain of $96.2 \%$ over CB-2. The failure load of the stone slab was $41.18 \mathrm{kN}$ corresponding to an increase in the capacity of $223.5 \%$ over CB-1 and an increase in the capacity of $25.4 \%$ over CB-2. The failure midspan deflection was $53.5 \mathrm{~mm}$ corresponding to an increase in the deflection of $276.8 \%$ over CB-1 and an increase in the deflection of $74.6 \%$ over CB-2. The end of four CFRP bars had no slip. The failure mode of CB-3 is shown in Figure 32, and the crack location is shown in Figure 33. From the crack location, symmetric distribution was presented. The failure mode of CB-2 is similar to the reinforcement concrete beams' failure mode in bending with GFRPS [28] or CFRPS [29].

\section{Discussion of Test Results}

4.1. Load Capacity and Slip Displacement. Test results (Table 8) showed that the use of NSM screw-thread steels and NSM 


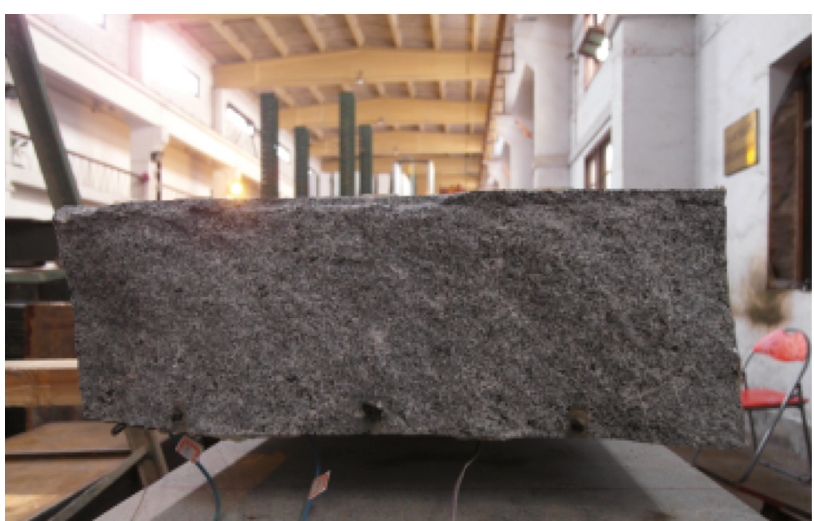

(a)

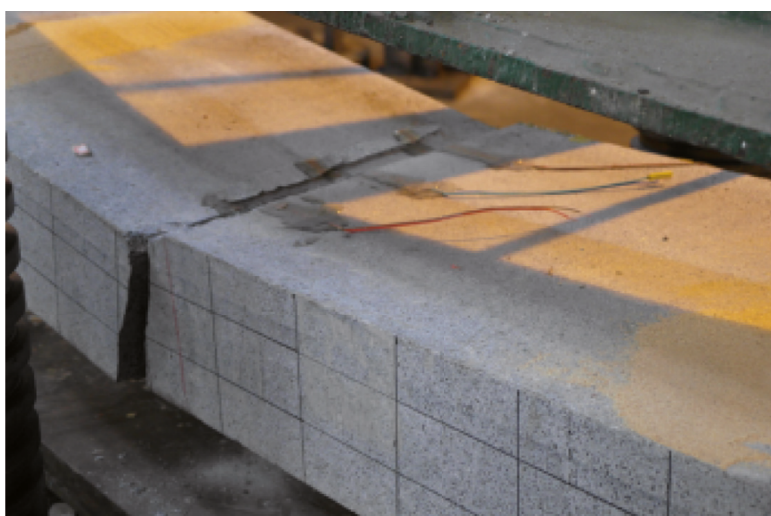

(b)

Figure 30: Failure mode of CB-2.

Loading point $\downarrow$
$140 \square$

Figure 31: Cracking location (mm).

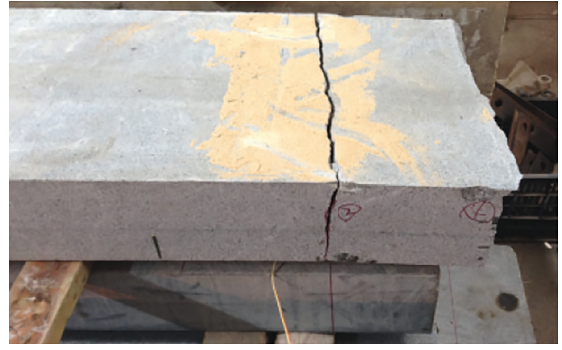

(a)

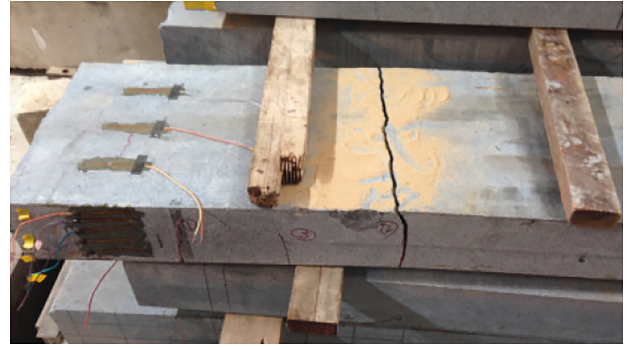

(b)

FIgURE 32: Failure mode of CB-3.

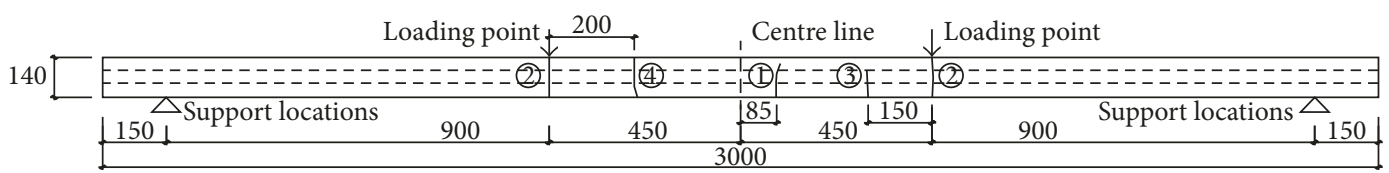

Figure 33: Cracking location (mm).

TABLE 8: Test result of NSM screw-thread steels and CFRP bars.

\begin{tabular}{|c|c|c|c|c|c|c|}
\hline Number of specimen & $F_{\mathrm{cr}}(\mathrm{kN})$ & $f_{\mathrm{cr}}(\mathrm{mm})$ & $F_{\mathrm{u}}(\mathrm{kN})$ & $f_{\mathrm{u}}(\mathrm{mm})$ & $F_{\mathrm{u}} / F_{\mathrm{cr}}$ & Failure mode \\
\hline B-1 & 24.18 & 3.89 & - & - & - & Brittle mode \\
\hline GB-1 & 30.71 & 5.05 & 19.18 & 12.16 & 0.62 & Brittle mode \\
\hline GB-2 & 28.03 & 4.63 & 19.59 & 16.72 & 0.70 & Brittle mode \\
\hline GB-3 & 28.15 & 4.30 & 15.96 & 17.17 & 0.57 & Brittle mode \\
\hline GB-4 & 34.18 & 5.01 & 21.09 & 24.43 & 0.62 & Brittle mode \\
\hline GB-5 & 34.76 & 5.39 & 38.76 & 122.5 & 1.12 & Ductile mode \\
\hline GB-6 & 37.65 & 5.32 & 56.44 & 174.50 & 1.50 & Ductile mode \\
\hline CB-1 & 24.59 & 5.50 & 12.75 & 14.2 & 0.52 & Brittle mode \\
\hline CB-2 & 30.09 & 5.20 & 32.85 & 30.65 & 1.26 & Brittle mode \\
\hline CB-3 & 28.35 & 5.68 & 41.18 & 53.50 & 1.45 & Ductile mode \\
\hline
\end{tabular}

Note. $F_{\mathrm{cr}}$, crack load; $F_{\mathrm{u}}$, failure load; $f_{\mathrm{u}}$, midspan deflection; $f_{\mathrm{cr}}$, midspan cracking deflection. 
TABle 9: Slip displacement of screw-thread steels and CFRP bars.

\begin{tabular}{lccccccc}
\hline Specimen & $1(\mathrm{~mm})$ & $2(\mathrm{~mm})$ & $3(\mathrm{~mm})$ & $4(\mathrm{~mm})$ & $5(\mathrm{~mm})$ & $6(\mathrm{~mm})$ \\
\hline GB-1 & 4 & 5 & 2 & 1 & 8 & - & - \\
GB-2 & 12 & No & No & No & 16 & - \\
GB-3 & 1 & 3 & 2 & 6 & 2 & - & - \\
GB-4 & 4 & 3 & No & No & No & No & - \\
GB-5 & No & No & No & No & No & No \\
GB-6 & No & 4 & No & No & No & No \\
CB-1 & 3 & No & 3 & No & No & No \\
CB-2 & 5 & No & No & No & No & No \\
CB-3 & No & & & & No \\
\hline
\end{tabular}

CFRP bars is an effective technique to enhance the crack load and failure load of the stone slab. When grooving height was changed for GB-2, an increase in the failure load of only $2.1 \%$ with respect to GB-1 could be obtained. When grooving width was changed for GB-3, an increase in the failure load of only $8.3 \%$ with respect to GB-1 could be obtained. When groove width and height were simultaneously increased as GB-4, an increase in the failure load of only $10 \%$ with respect to GB-1 could be obtained. Increasing the reinforcement ratios of screw-thread steels (GB-4, GB-5, and GB-6) from $5 \mathrm{C} 6,5 \mathrm{C} 8$, to $7 \mathrm{C} 8$, which corresponds to a $40 \%$ increase in the reinforcement ratios of screw-thread steels, led to an increase in the failure load of $83.8 \%$ and $167.2 \%$ over GB-4, respectively. Of the three stone slabs with CFRP bars (CB-1, CB-2, and CB-3), increasing reinforcement ratios of CFRP bars from $2 \mathrm{~A} 6,3 \mathrm{~A} 6$, to $4 \mathrm{~A} 6$ corresponds to a $50 \%$ and $100 \%$ increase in the amount of CFRP bars over CB-1, which led to an increase in the failure load of 157.6 and $223.0 \%$ over CB-1, respectively.

From the above discussion, it can be concluded that when stone slabs were destroyed in the tension zone and exited work. The capacity was mainly supported by screwthread steels and CFRP bars. So groove size has no decisive influence on the failure load. Instead, it reduced slab's flexural stiffness. Obviously, improving reinforcement ratios is more effective to improve flexural performance than increasing groove size for enhancing the failure load. These comparisons seem to indicate that the most efficient way of increasing the failue load of the stone slab is improving reinforcement ratios. The test result is shown in Table 8.

From Table 8, comparing GB-1 NSM screw-thread steels with CB-1-3 NSM CFRP bars under the same grooving dimensions, CB-1, CB-2, and CB-3 with the reinforcement ratios, respectively, $0.101 \%, 0.151 \%$, and $0.202 \%$ have the nearly same cracking load with GB-1 with the reinforcement ratio $0.254 \%$, but the former middeflection of cracking increased, respectively, by $8.9 \%, 9.9 \%$, and $12.4 \%$ compared with the latter; after cracking, the failure load of CB-2 and CB-3 increased, respectively, by $71.2 \%$ and $114.7 \%$, the middeflection of failure for CB-1, CB-2, and CB-3 increased, respectively, by $16.7 \%, 152.0 \%$, and $340 \%$ compared with GB-1. The main reason was that the tensile strength of CFRP bars was larger than screw-thread steels. We can conclude that the CFRP bars are more effective to resist the flexural loading than the screw-thread steels under the same reinforcement ratios and groove dimensions.

From the failure mode and Table 8, two failure mechanisms were observed, namely, brittle failure of low reinforcement ratios of screw-thread steels and CFRP bars and ductile failure of high reinforcement ratios. The slip of screw-thread steels and CFRP bars which were prevented by high-strength adhesive and the slip displacement is shown in Table 9.

From Table 9, when the reinforcement ratios (GB-5, GB-6, and GB-6) are high, the screw-thread steels have no slip; when the reinforcement ratios (GB-1-4, CB-1, and CB-2) are low, the slip displacement is relatively obvious.

4.2. Analysis of Midspan Deflection. From Figure 34(a), pure stone slab B-1 under monotonic four-point bending load clarified a linear elastic behavior up to failure. The midspan deflection of failure was only $3.89 \mathrm{~mm}$.

From Figure 34(b), brittle failure of specimen GB-1-3 was divided into two stages: before cracking and after cracking. Before cracking, deflection was of linear elastic behavior. After cracking, the deflection first decreased and then increased; this corresponded to crack appearance, the stone slab' tension zone exited work, load rapidly descended, and midspan deflection increased very fast. When steel bars attained ultimate tension strain, the curve became descending curve which had a very small slope. It is clear from Figure 34(b) that increasing groove width or groove height could decrease the middeflection of cracking with the same reinforcement ratios.

From Figure 34(c), ductile failure of GB-5 and GB-6 was divided into four stages: before cracking, after cracking, multiple cracking stage, and failure stage. Before cracking, deflection was in linear elastic behavior, and the cracking load increased with the increase of reinforcement ratios. After cracking, the loading repeatedly decreased and increased, midspan deflection increased, and curves showed multiple descending stage and increasing stage. This corresponded to the appearance of each crack. When the failure load was attained, steel bars yielded, loading variation was small, and midspan deflection rapidly increased. Finally, loading-deflection changed mildly, almost a horizontal line. It is obvious that increasing reinforcement ratios can remarkably increase the ductility. 


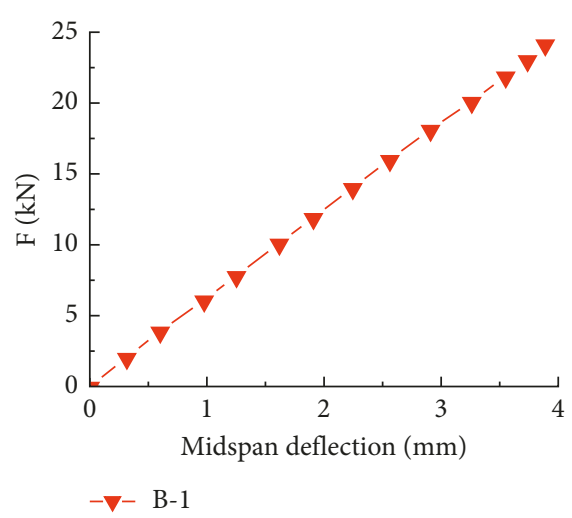

(a)

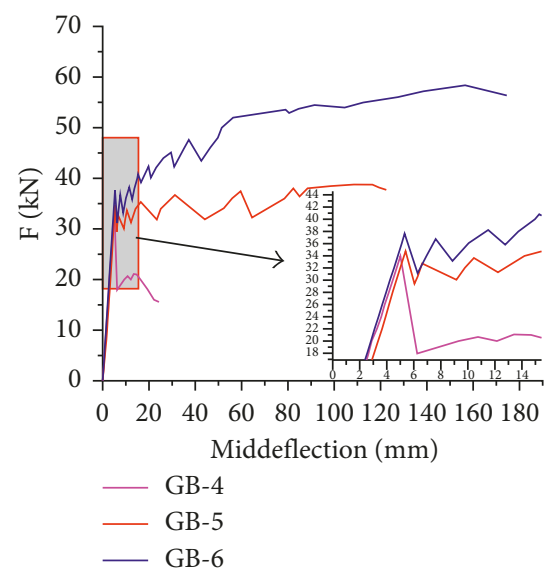

(c)

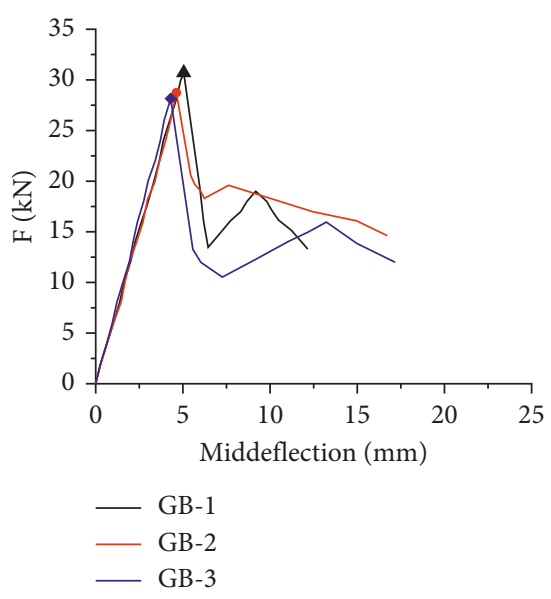

(b)



(d)

Figure 34: Midspan deflection curves: (a) B-1; (b) GB-1 4; (c) GB-4 6; (d) CB-1 3.

From Figure 34(d), failure phenomena of CB-1 3 were similar to GB-1 4, and the only difference is that when CFRP bars attained failure of ultimate tension strain, the loading-deflection curve was an increasing straight line with a greater slope. The main reason was that steel bars as an elastic-plastic material have an obvious yield point, but CFRP bars as the linear elastic material have no yield point. This indicated that the stone slabs adopting NSM CFRP bars have a greater capacity and ductility. The wave shape of the curves corresponds to the appearance of each crack.

4.3. Tension Strain of Screw-Thread Steels and CFRP Bars. Figure 35 shows the variation of imposing load and the measured strains in tension reinforcement during loading. The location of strain measurement of screw-thread steels' strain and CFRP bars' strain is shown in Figure 12.

From Figure 35, before cracking, the variation of the loading strain curve remains almost the same for each specimen; meanwhile, the screw-thread steels and CFRP bars lie in the linear elastic stage. Strain of screw-thread steels and CFRP bars was about 400 500 which is far lower than the ultimate tensile strain of them. This clarified that the screw-thread steels and CFRP bars together with the stone slab resisted the flexural deformation; the strain of screwthread steels and CFRP bars was not fully utilized. After cracking, the stone slab exited working and the load was borne by screw-thread steels and CFRP bars which located in the crack; meanwhile, the screw-thread steels and CFRP bars outside crack and among crack lied in the elastic stage and the strain decreased with the loading decreasing.

In view of Figure 35, the contrast among GB-1 3 showed that the loading-strain curves of the midspan, left loading point, and right loading point before cracking were almost consistent, and increasing height and width of groove cannot obviously improve crack strain and failure strain of steel bars. So, the groove dimension did not influence the action of steel bar's strain. The contrast among CB-1, CB-3, and GB-4 6 found that maximum strain of CB-1 and GB-4's screw-thread steels and CFRP bars with low reinforcement ratios was, respectively, $4533 \mu \varepsilon, 380 \mu \varepsilon, 328 \mu \varepsilon$, and $10503 \mu \varepsilon$, $6716 \mu \varepsilon, 350 \mu \varepsilon$. Maximum strain of CB-3, GB-5, and GB-6 with high reinforcement ratios was, respectively, $1236 \mu \varepsilon$, $5937 \mu \varepsilon$, and $1071 \mu \varepsilon, 23025 \mu \varepsilon, 7073 \mu \varepsilon$ and $13968 \mu \varepsilon$, $16338 \mu \varepsilon, 14207 \mu \varepsilon$. We can conclude that the reinforcement ratio influences the action of screw-thread steels and CFRP bars' strain. With increasing of reinforcement ratios, the strength of steel bars and CFRP rod can be fully utilized. 



(b)
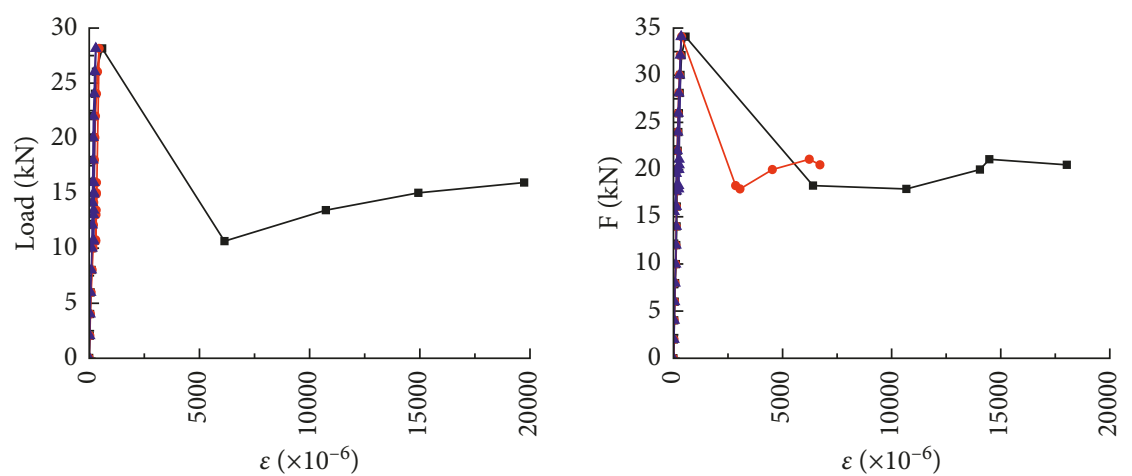

$\rightarrow$ Midspan

- Left loading point

- Midspan

$\rightarrow$ Left loading point

$\_$Right loading point

(c)

(d)
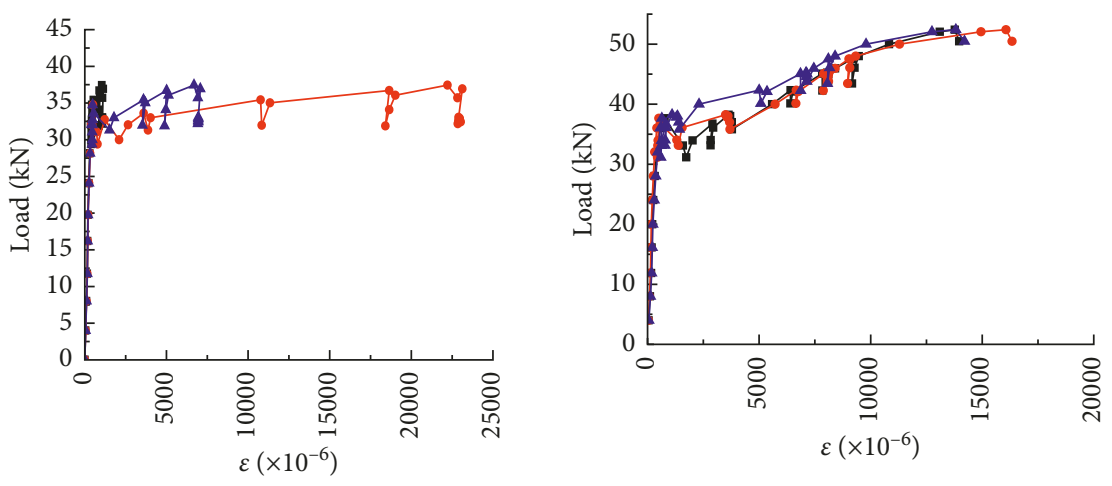

$\rightarrow$ Midspan

$\rightarrow$ Left loading point

- Midspan

$\rightarrow$ Left loading point

$\_$Right loading point

(e)

(f)

Figure 35: Continued. 


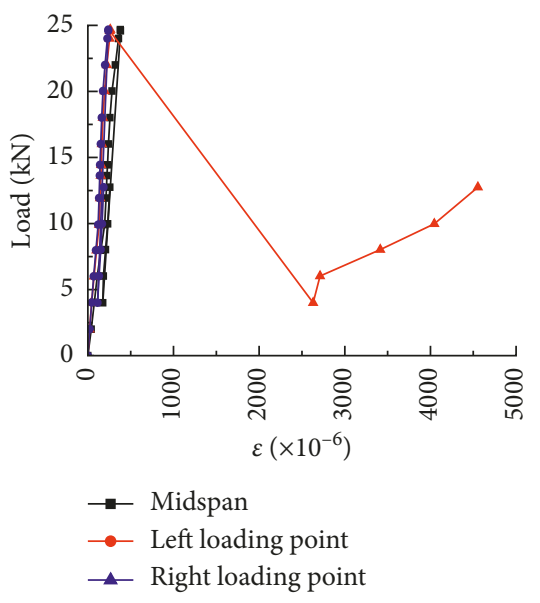

(g)

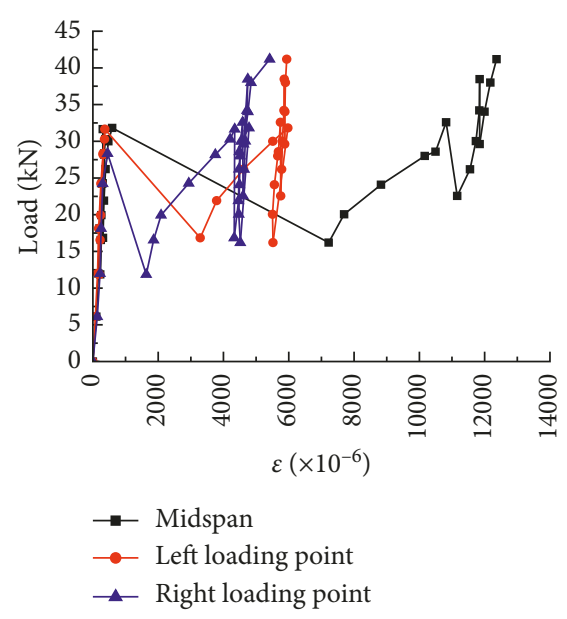

(h)

Figure 35: Strain screw-thread steels and CFRP bars: (a) GB-1; (b) GB-2; (c) GB-3;(d) GB-4; (e) GB-5; (f) GB-6; (g) CB-1; (h) CB-3.

We must note that GB-1's and GB-2's steel strain was descending after crack; this can be explained that when the tension strain of steel bars attained the maximum value, the debonding failure happened between stone slab and steel bars; and steel bars is no longer loaded and unloaded continuously.

4.4. Tension Strain and Compression Strain of Stone Slab. The load versus stone slab compressive strain at the top of the slabs is presented in Figure 36. The compressive strains of all the strengthened stone slabs except GB-6 were less than the compressive strain of granite stone materials (Table 3). GB-6 had a greater reinforcement ratio than other stone slabs which made the compressive strength of the stone slab utilized fully. Failure strength of GB-5 and GB- 6 is greater than the pure stone slab. All the strengthened stone slabs show linear variation in strain up to the stone slab cracking.

Compressive strain of GB-1, GB-2, and GB-3 with the same reinforcement ratios but different grooving dimensions was different (Figure 36(b)). During the cracking stage, increasing grooving width (GB-3) and increasing grooving height (GB-2) had a less compressive strain than GB-1. During the failure stage, increasing grooving width (GB-3) and increasing grooving height (GB-2) had a larger compressive strain than GB-1. The main reason was that increasing the grooving height and grooving width weakened the initial flexural stiffness during the crack stage, so the compressive strain was decreased; however, during the failure stage, the bars bear the loading, and the stone slab was continually compressed; it leads to the increase of compressive strain.

Compressive strain of GB-4, GB-5, and GB-6 with the increase of reinforcement ratios from $0.254 \%, 0.449 \%$, to $0.629 \%$ (Figure 36(c)) increased. During the cracking stage, the increase of the reinforcement ratios had a greater compressive strain than GB-1. During the failure stage, the increase of the reinforcement ratios had a greater compressive strain than GB-1. The main reason was that increasing the reinforcement ratios led to increase of the grooving dimension further weakens the initial flexural stiffness during crack stage, so the compressive strain was decreased; however, during the failure stage, the bars bore the loading, and the stone slab was continually compressed; it leads to the increase of compressive strain. The increase in reinforcement ratios in strengthening the stone slab caused the magnitude of strains to increase significantly. However, with the increase of the reinforcement ratio, the development of compressive strain was delayed (Figure 36(c)). Meanwhile, combined with the failure mode of GB-4, GB-5, and GB-6 (Figures 22, 24, and 26), this illustrated that with the increase of reinforcement ratios, the compressive strength of the stone slab can be fully utilized, and the ductility was improved.

Compressive strain of CB-1, CB-2, and CB-3 (Figure 36(d)) with the increase of the reinforcement ratios (CFRP) from $0.101 \%, 0.151 \%$, to $0.202 \%$ is similar to GB-4, GB-5, and GB-5, but the development of compressive strain had no obvious rules. This is caused by the initial defect of the stone slab.

Table 10 shows the tension strain of the midsection, and the midsection tension zone's tensile strain during cracking attained maximum. After cracking, the stone's strain in the tension zone was rapidly decreasing and exiting working due to presence of cracking. Midsection tension strain of specimens whose reinforcement ratios (GB-5, GB-6, CB-2, and CB-3) were relatively high was higher than that of other specimens, but not attaining the ultimate tensile strain of stone materials. Increasing the reinforcement ratio may improve tensile strain of the stone slab. The reason was that the higher the reinforcement ratio, the larger the bond area; then the bonding action is stronger between the stone slab and steel bars or CFRP bars; and the integrity was very well. The appearance of cracking can be delayed by the bonding action so that the tensile strain of stone materials can be fully utilized.

The effect of the groove dimension on the tensile strain of stone slabs is obvious. Increasing the grooving height and width weakens the tension strain of the stone slab during the 


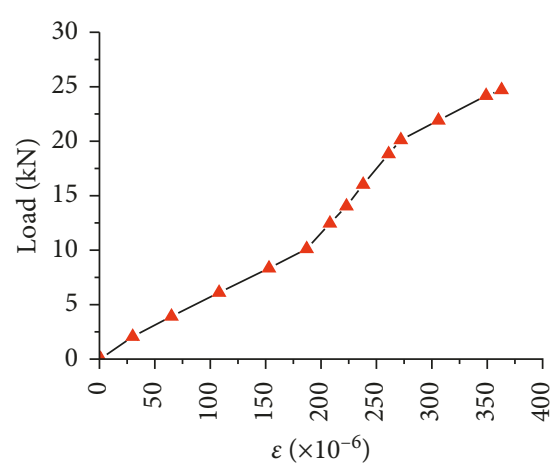

-

(a)

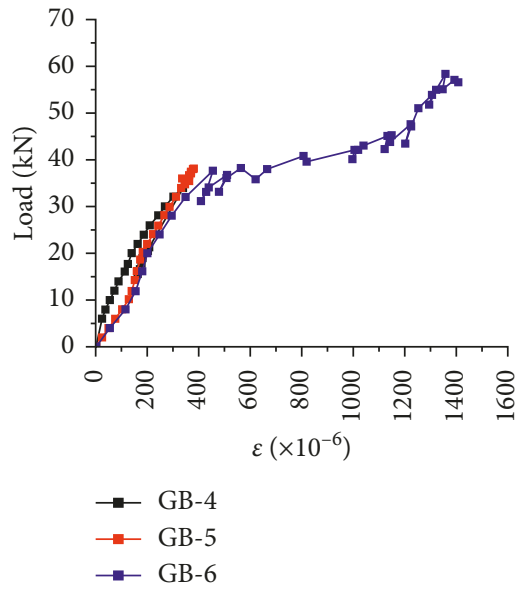

(c)

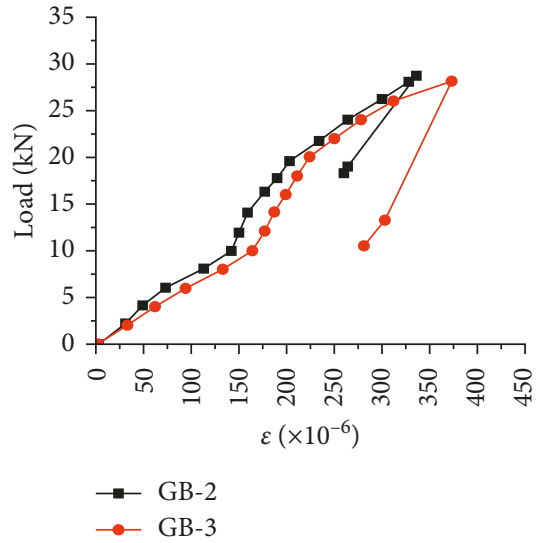

(b)

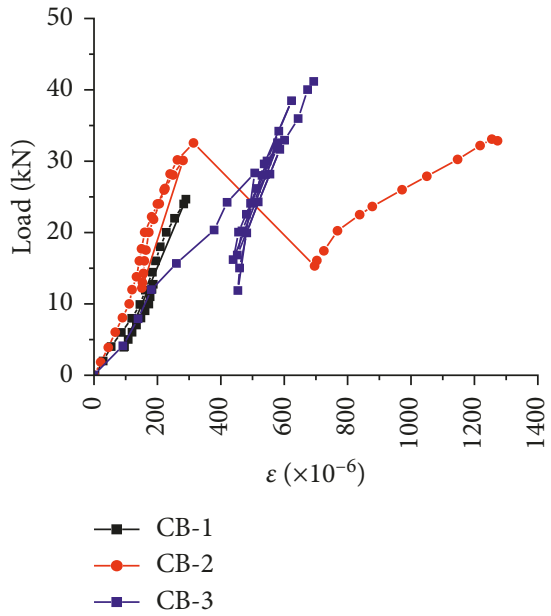

(d)

FIGURE 36: Load midspan section strain cures of stone slab top: (a) B-1; (b) GB-2-3; (c) GB-4-6; (d) CB-1-3.

TABLE 10: Strain value of midspan top and bottom of the slab.

\begin{tabular}{lccccccccccc}
\hline Label of specimen & & B-1 & GB-1 & GB-2 & GB-3 & GB-4 & GB-5 & GB-6 & CB-1 & CB-2 & CB-3 \\
\hline \multirow{2}{*}{ Cracking stage } & $\varepsilon_{\mathrm{c}}(\mu \varepsilon)$ & 363 & 335 & 319 & 311 & 328 & 332 & 353 & 290 & 281 \\
\multirow{2}{*}{ Failure stage } & $\varepsilon_{\mathrm{t}}(\mu \varepsilon)$ & 409 & 447 & 440 & 418 & 508 & 487 & 558 & 459 & 532 \\
& $\varepsilon^{\prime}{ }_{c}(\mu \varepsilon)$ & 363 & 220 & 245 & 267 & 163 & 405 & 1728 & 187 & 1329 & 693 \\
& $\varepsilon^{\prime}{ }_{t}(\mu \varepsilon)$ & - & 294 & 308 & 230 & 251 & 340 & - & 223 & - & - \\
\hline
\end{tabular}

Note. $\varepsilon_{\mathrm{t}}$ and $\varepsilon_{\mathrm{t}}^{\prime}$, average value of tension strain of stone slab bottom; $\varepsilon_{\mathrm{c}}$ and $\varepsilon_{\mathrm{c}}^{\prime}$, average value of compressive strain of stone slab top.

cracking stage. However, during the failure stage, the tension strain of the stone slab depended on the cracking location. The tension strain was large when the cracking is away from the midspan (GB-1). The tension strain was small when the cracking is near the midspan (GB-1 and GB-3).

4.5. Sectional Strain Profile of Stone Slabs. Strain gauges were attached along the height of the stone slab at the midspan (Figure 13(b)), and measured variation of sectional strain in the stone slab over the depth of slabs B-1, GB-1-6, and CB1-3 at different load levels is presented in Figure 37.

For B-1, the strain variation was linear at the commencement of loading (up to $10 \mathrm{kN}$ ) and the variation increases with higher load levels. Height of the neutral axis is $84 \mathrm{~mm}$.

Neutral axis height of GB-1, GB-2, and GB-3 with the same ratio of reinforcement but different grooving dimension is, respectively, $85 \mathrm{~mm}, 85 \mathrm{~mm}$, and $85 \mathrm{~mm}$. Meanwhile, the strain deviation almost keeps invariant. So, the grooving dimensions have almost no effect on the neutral height axis.

The neutral axis height of GB-4, GB-5, and GB- 6 with the increase of the reinforcement ratio (steel reinforcements) from $0.254 \%, 0.449 \%$, to $0.629 \%$ is, respectively, $88 \mathrm{~mm}$, $78 \mathrm{~mm}$, and $76 \mathrm{~mm}$. The neutral axis height decreases with the increase of the reinforcement ratio. Meanwhile, the strain deviation increases with the increase of the 


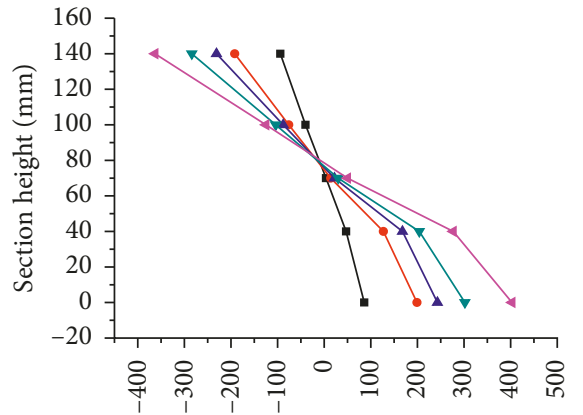

$\varepsilon\left(\times 10^{-6}\right)$

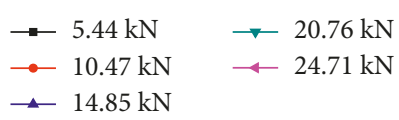

(a)



$\rightarrow 4.97 \mathrm{kN} \quad \checkmark 20.24 \mathrm{kN}$

$\rightarrow 9.98 \mathrm{kN} \quad \longleftarrow 24.88 \mathrm{kN}$

$\neg 14.68 \mathrm{kN} \rightarrow 28.74 \mathrm{kN}$

(c)

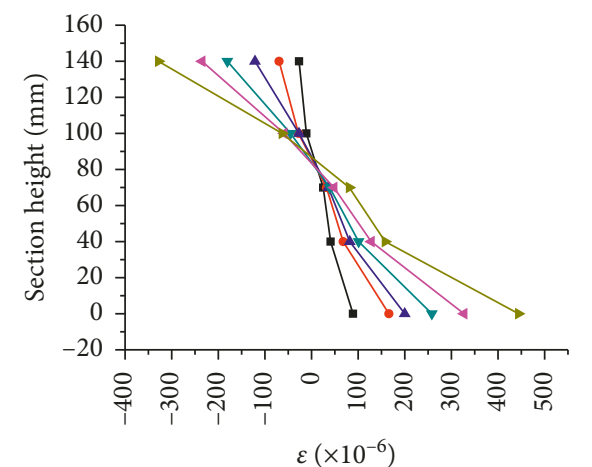

$$
\varepsilon\left(\times 10^{-6}\right)
$$



$\neg 17.72 \mathrm{kN} \rightarrow 33.94 \mathrm{kN}$

(e)

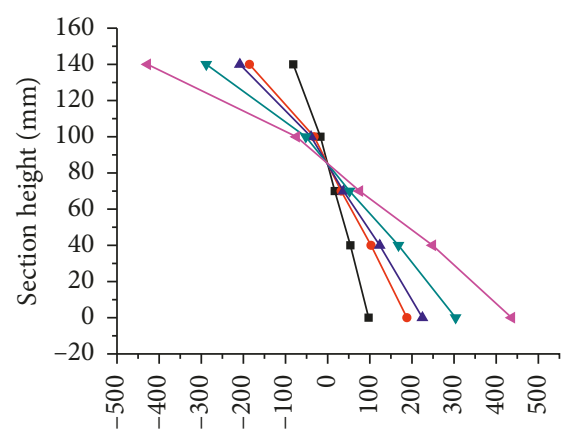

$\varepsilon\left(\times 10^{-6}\right)$

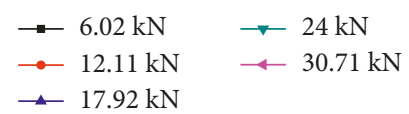

(b)

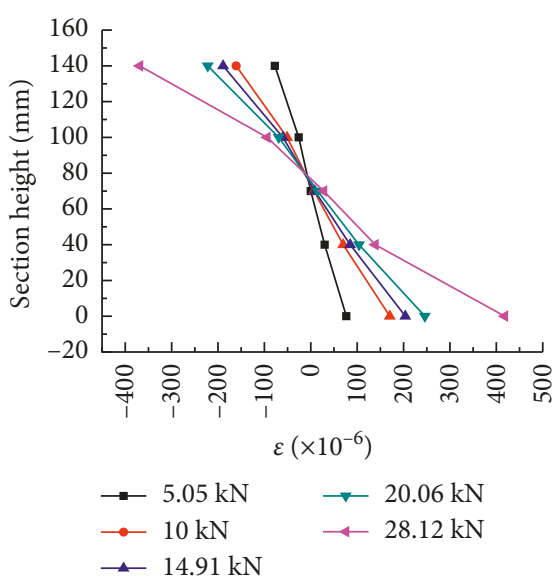

(d)

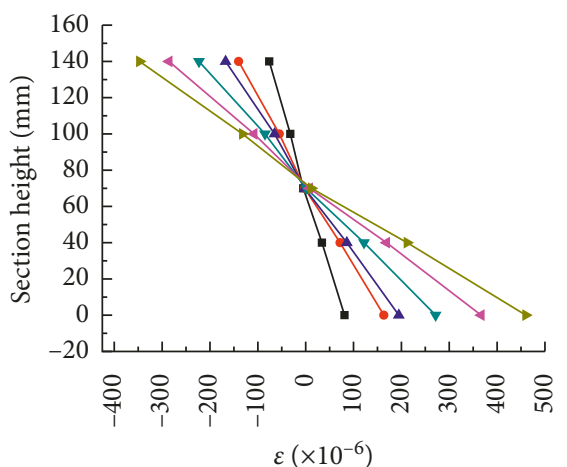

$$
\begin{array}{ll}
\longrightarrow 5.98 \mathrm{kN} & \rightarrow 24.09 \mathrm{kN} \\
\rightarrow-11.93 \mathrm{kN} & \leftarrow 29.94 \mathrm{kN} \\
\leftarrow-17.43 \mathrm{kN} & \rightarrow-34.76 \mathrm{kN}
\end{array}
$$

(f)

FIgure 37: Continued. 




(g)

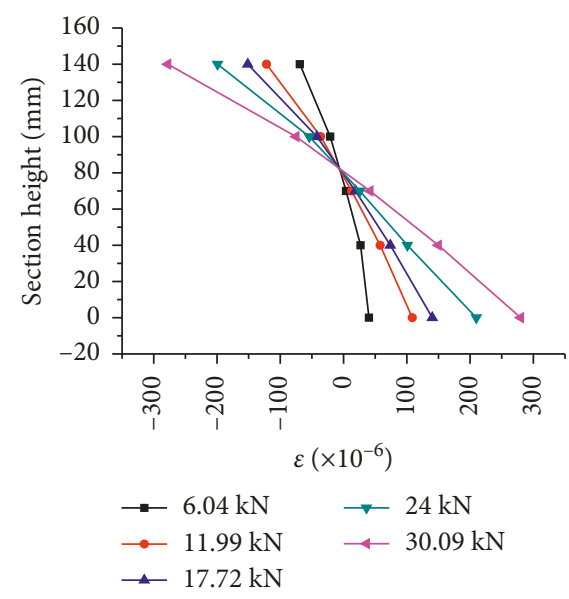

(i)

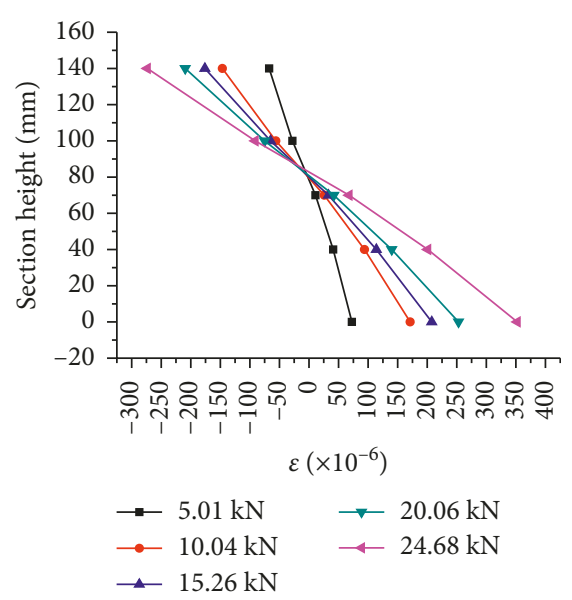

(h)

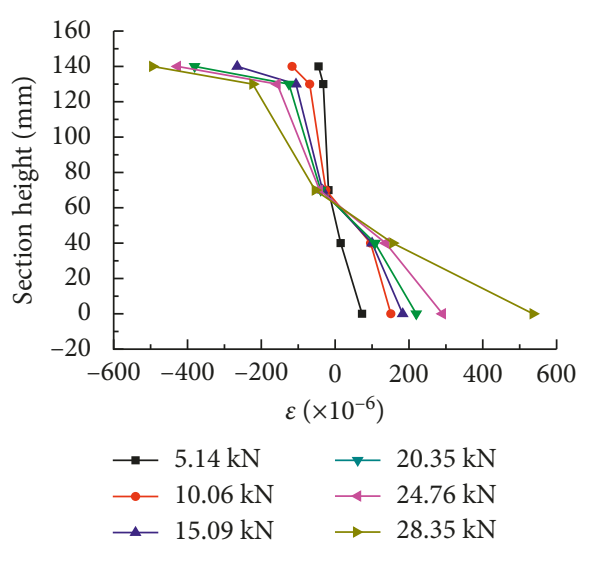

(j)

Figure 37: Sectional strain variation at the midspan: (a) B-1; (b) GB-1; (c) GB-2; (d) GB-3; (e) GB-4; (f) GB-5; (g) GB-6; (h) CB-1; (i) CB-2; (j) CB-3.

reinforcement ratio. The main reason was that increasing the reinforcement ratio limits the crack height of the stone slab and increases the height of the compression region.

The neutral axis height of CB-1, CB-2, and CB-3 with the increase of the reinforcement ratio from $0.101 \%, 0.151 \%$, to $0.202 \%$ is, respectively, $87 \mathrm{~mm}, 85 \mathrm{~mm}$, and $72 \mathrm{~mm}$. The neutral axis height decreases with the increase of the reinforcement ratio. This is consistent with GB-4, GB-5, and GB-6. Meanwhile, the strain deviation increases with the increase of the reinforcement ratio. In the GB-5, the specimen shows the less transverse strain compared with GB-4 and GB-6, and the main reason was that the bars' slip displacement is not uniform.

4.6. Joint Work Characteristic of Steel Bars, CFRP Bars, and Stone Slabs. From Figure 38, it is shown that before cracking, the strain of screw-thread steels and stone slabs remained increased simultaneously, and the strain is almost the same. This indicated that before cracking, steel bars, CFRP bars, and stone slabs can work together well. After crack, tensile strain of the stone slab in the tension zone of the specimens CB-3 and GB-3 6 whose cracking location is close to the midspan was rapidly decreased. However, the strain of screw-thread steels and CFRP bars was rapidly increased. Except GB-1 and GB-2, the reason was that the debonding failure happened between steel bars and stone slabs. Tensile strain of the stone slab and screw-thread steels and CFRP bars in the tension zone of the specimens CB-1 and GB-1 3 whose cracking location was away from the midspan rapidly decreased with the increasing of load. It is obvious that before cracking, the load was simultaneously borne by the stone slab and screw-thread steels and CFRP bars. After cracking, the loading was borne by only steel bars and CFRP bars which were located in the crack. The slip of steel bars and CFRP bars and splitting of the stone slab were found before flexural failure. So, the common working performance of the stone slab and screw-thread steels and CFRP bars was very well. The groove dimension, reinforcement ratios, and reinforcement type have little significant influence on the joint working performance. However, we can find that adopting the CFRP bars (CB-1 and $\mathrm{CB}-3$ ) has a better joint working performance than screw-thread steels (GB-1, GB-2, and GB-3).

4.7. Strength Study. In this section, we investigate the parameter's influence including reinforcement ratios, reinforcement 

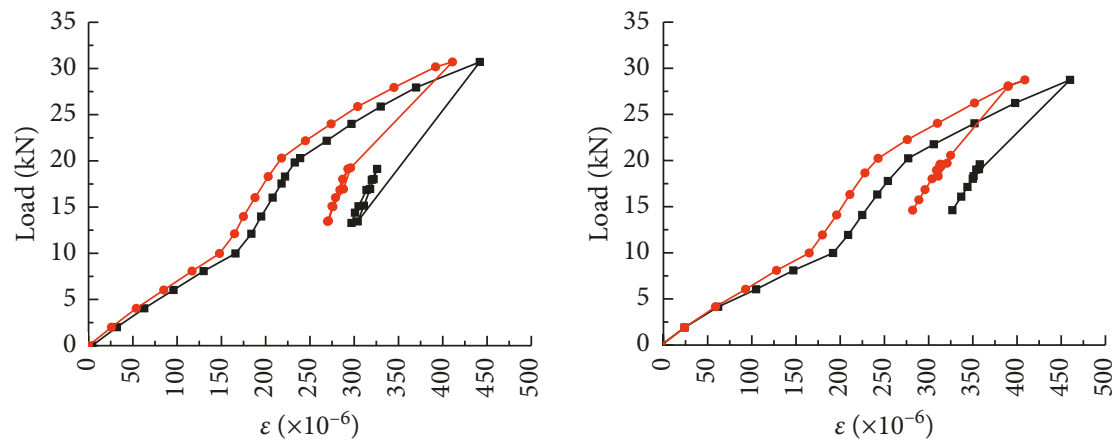

$\rightarrow$ Stone slab

(a)

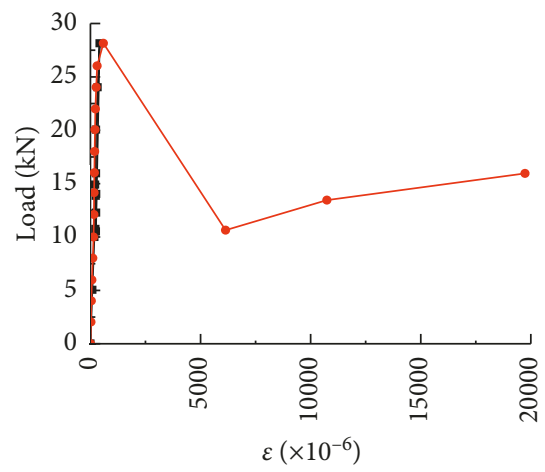

- Stone slab

$\rightarrow$ Steel bars

(c)

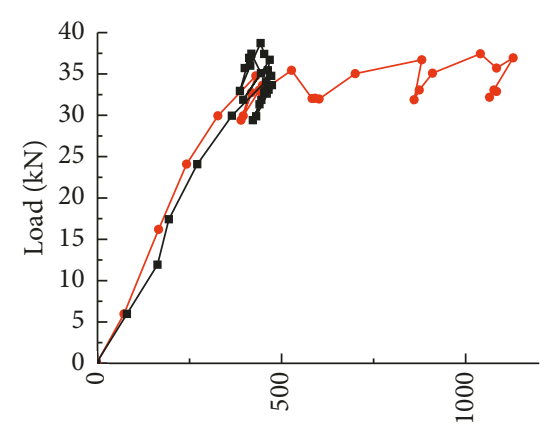

$\varepsilon\left(\times 10^{-6}\right)$ $\rightarrow$ Stone slab

- Steel bars

(b)



$\rightarrow$ Steel bars

$\rightarrow$ Stone slab

(d)



$\rightarrow$ Steel bars

$\rightarrow$ Stone slab

(e)

Figure 38: Continued. 


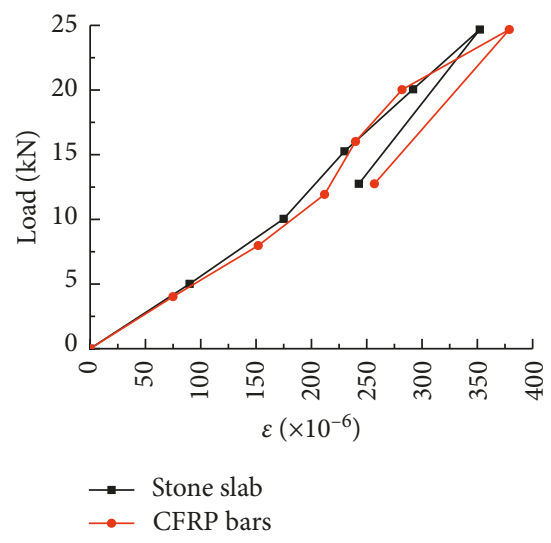

(g)

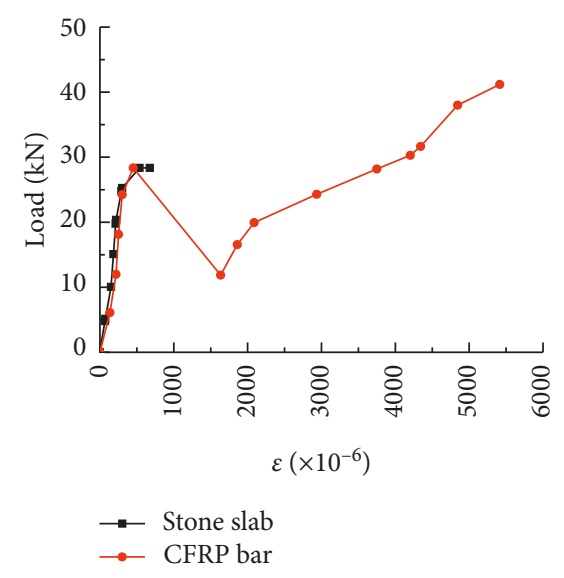

(h)

FIgURe 38: Strain comparison between screw-thread steels and CFRP bars and stone slab: (a) GB-1; (b) GB-2; (c) GB-3; (d) GB-4; (e) GB-5; (f) GB-6; (g) CB-1; (h) CB-3.

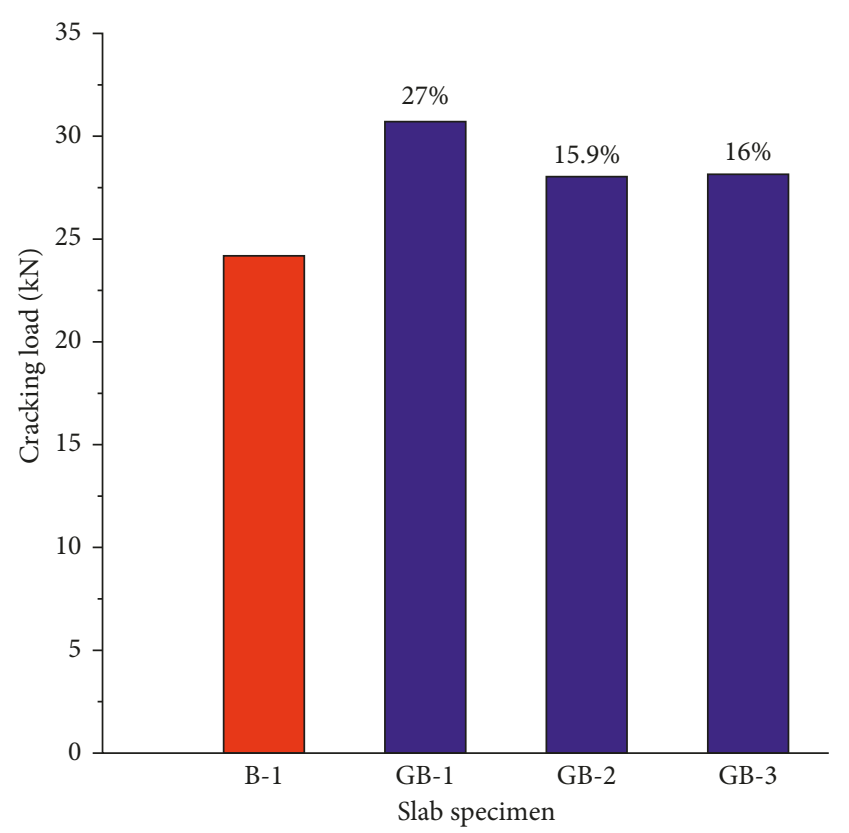

Control slab

Strengthened slab

Figure 39: Cracking load.

materials, and groove dimensions on the cracking load, midspan cracking deflection, failure load, and midspan failure deflection.

4.7.1. The Effect of NSM Groove Dimensions (GB-1-3). The influence of NSM groove dimensions on the NSM strengthening of the stone slab is presented in Figures 39-41. The same reinforcement ratios (GB-1-3) were used to investigate this effect. The figure demonstrates that increasing groove height or groove width decreases the cracking load, midspan cracking deflection, and ultimate load. The main reason was that the section stiffness was weakened by grooving.

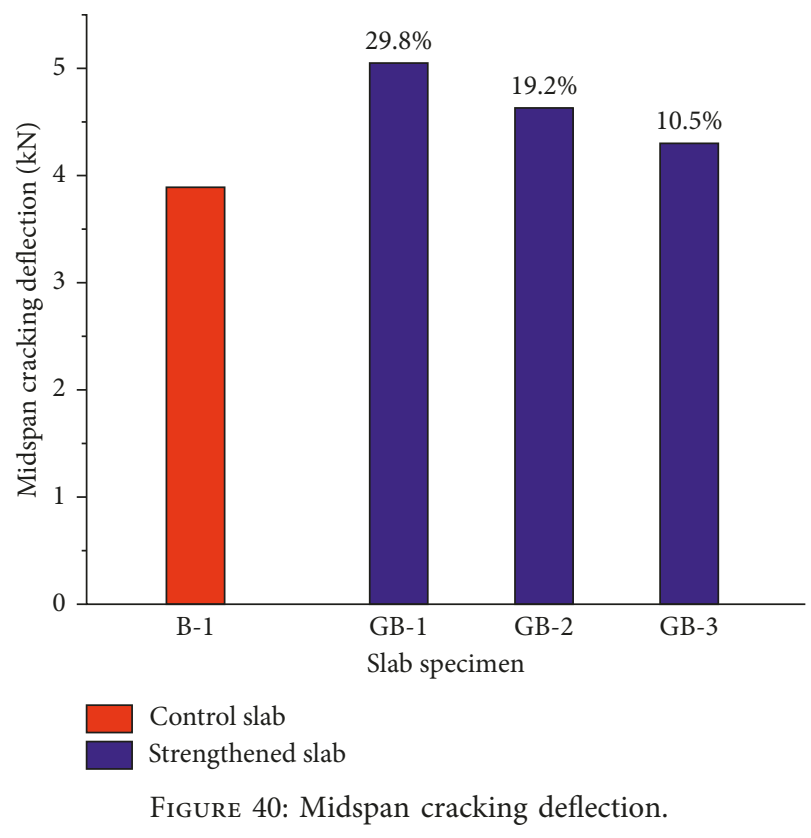

4.7.2. The Effect of NSM Reinforcement Amount on Strengthening (GB-4-6). The influence of NSM reinforcement ratios on the stone slab is presented in Figures 42-44. The figure demonstrates that increasing NSM reinforcement ratios increases the cracking load, midspan cracking deflection, and ultimate load. The more the reinforcement ratios, the larger the improvement. CB-1, CB-2, and CB-3 have the same trend with GB-4-6 with the increase of reinforcement ratios.

4.7.3. The Effect of Type of NSM Reinforcement on Stone Slabs $(C B-3$ and $G B-1)$. The effect of NSM reinforcement type on the performance by strengthening is presented in Figures 45-47. The similar amount of reinforcement ratios (CB-1 and CB-3 for $0.254 \%$ and $0.202 \%$ ) were used to investigate this effect. The CFRP bars increase the ultimate load and 


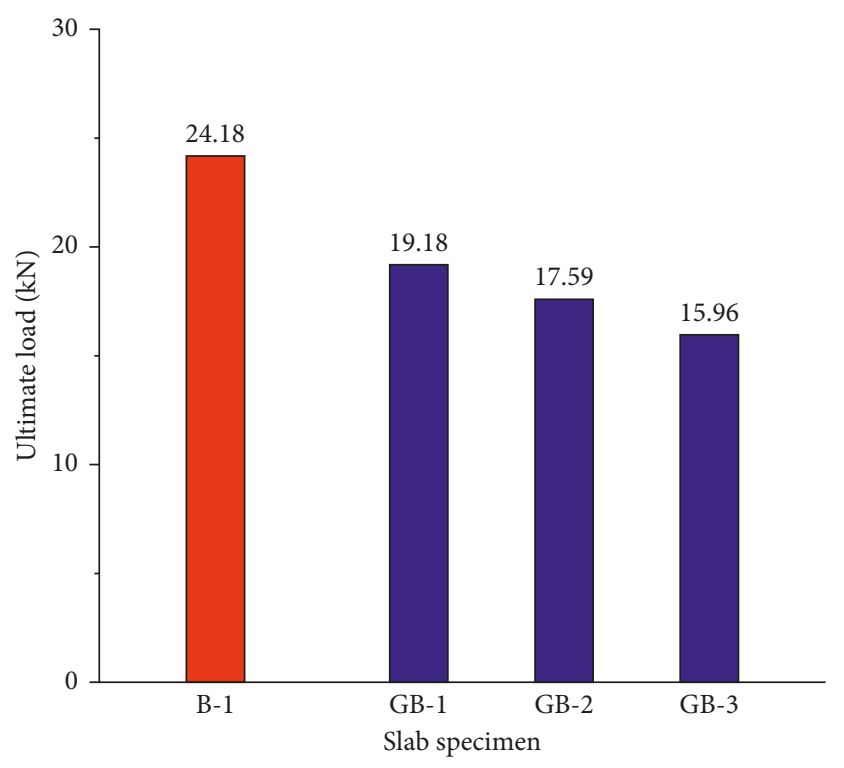

Control slab

Strengthened slab

Figure 41: Ultimate load.

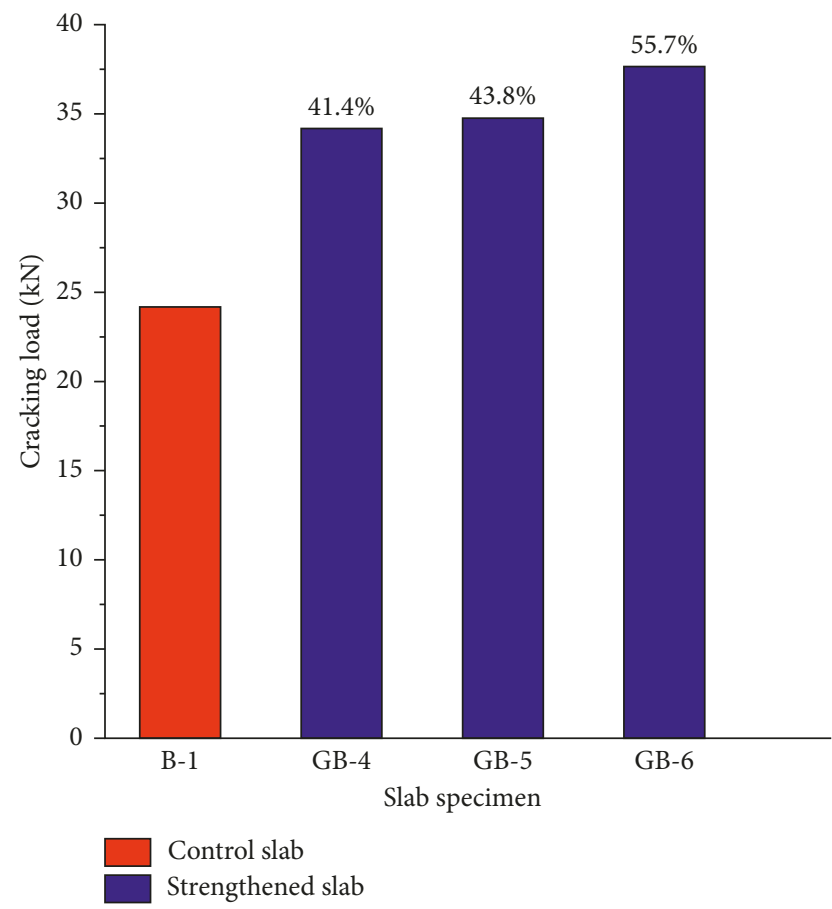

Figure 42: Cracking load.

midspan cracking deflection more than $114.7 \%$ and $11.5 \%$, respectively, compared with the screw-thread steels due to higher tensile strength. Thus, it is necessary to use NSM CFRP bars to increase the ultimate load capacity of stone slabs. The results were similar to those in [30].

4.8. Strength Calculation. This section aimed at the flexural progress of the stone slab with NSM screw-thread steels and

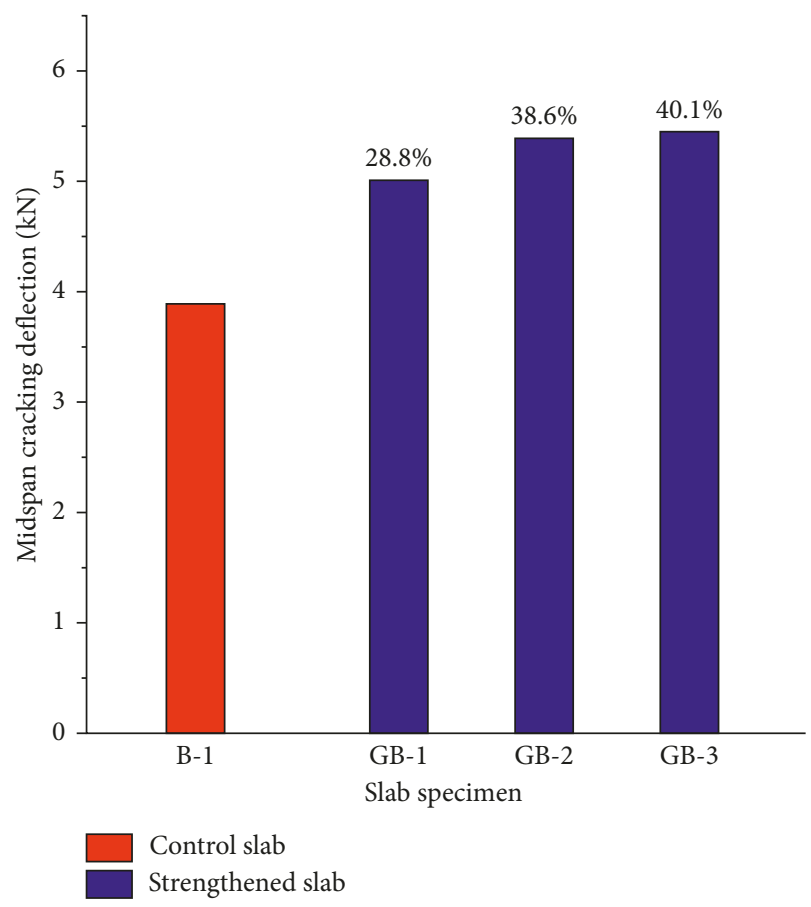

FIgURE 43: Midspan cracking deflection.

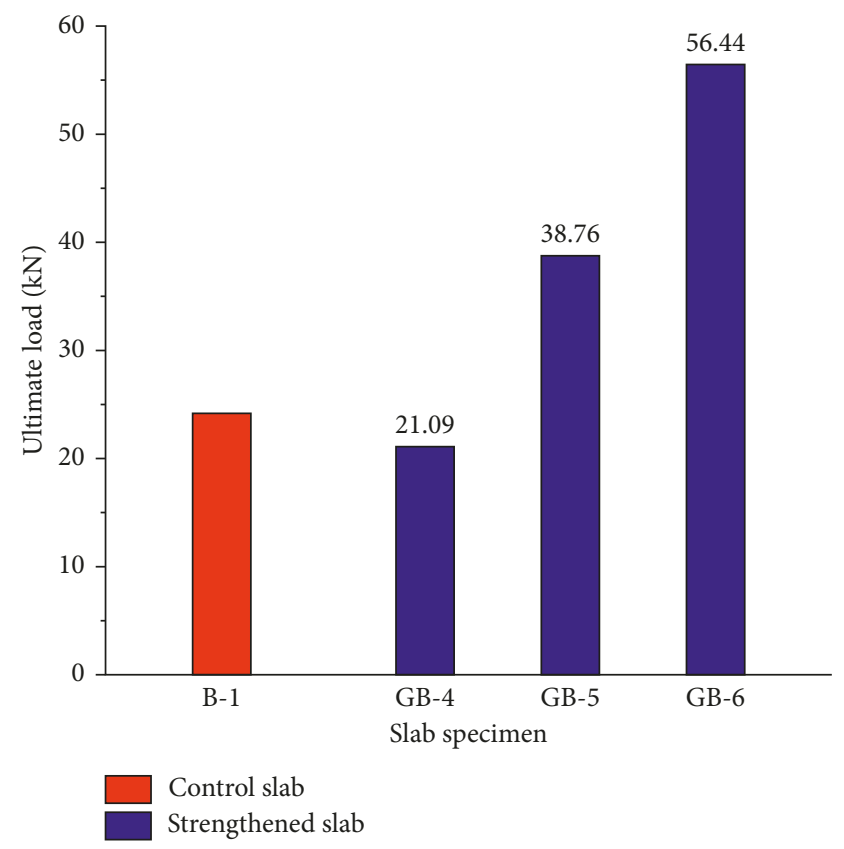

FIgURE 44: Ultimate load.

FRP and established the mechanical model and then calculating the flexural strength, cracking and ultimate strength. Meanwhile, this can be used as a guideline for future engineering application.

4.8.1. The Failure Mode and Cross-Sectional Stress Profile of Stone Slab with Screw-Thread Steels and CFRP. The failure mode of stone slabs with screw-thread and FRP can be 


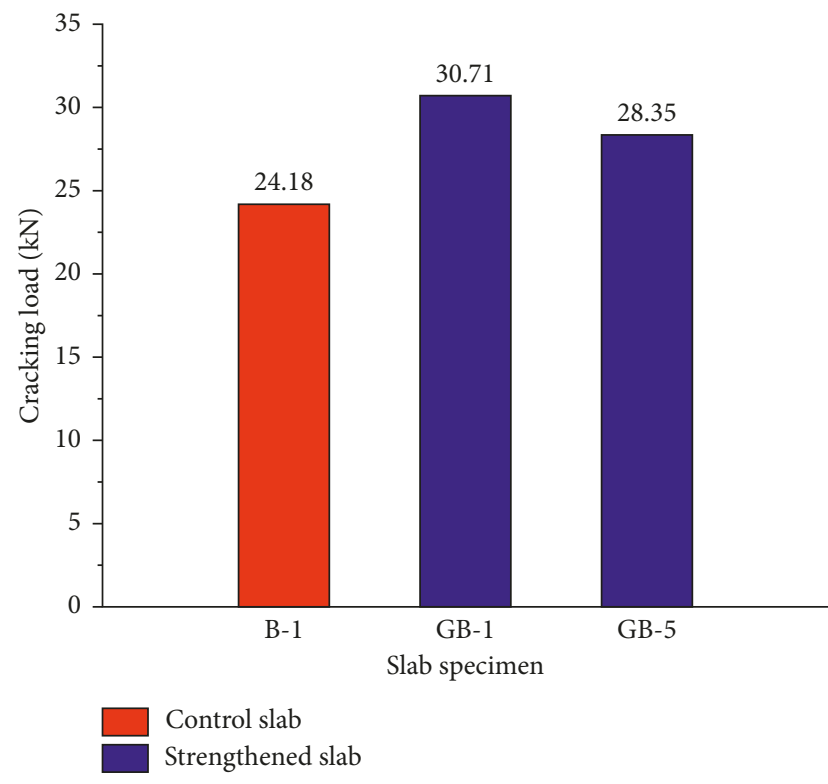

FIgURE 45: Cracking load.

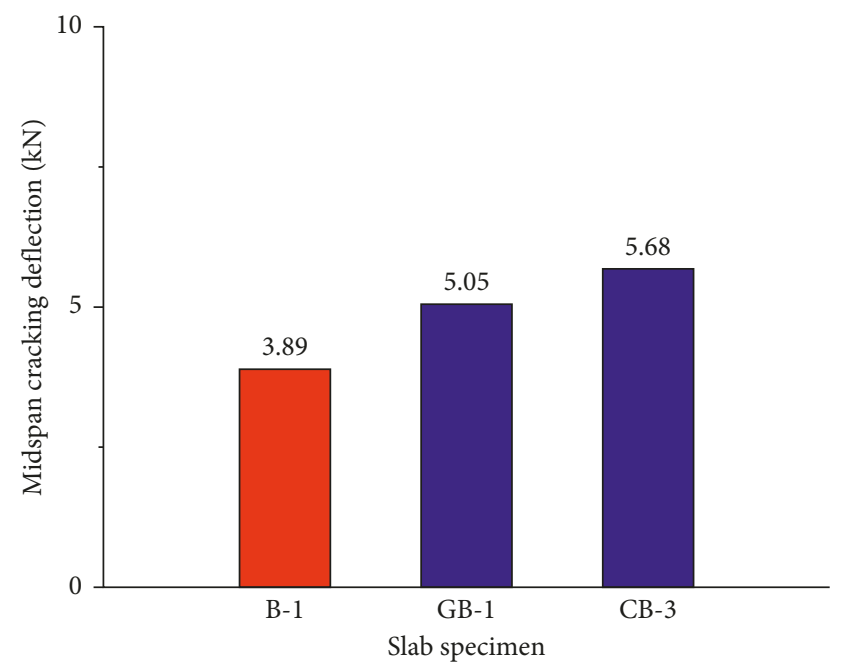

Control slab

Strengthened slab

FIgURE 46: Midspan cracking deflection.

divided into brittle failure mode and ductility failure mode according to reinforcement ratios. From the experiment phenomenon and moment middeflection curves, the obvious curve turning was observed from the moment middeflection curves, and those turnings represented the appearance of the crack in the stone slab. Meanwhile, we can determine the crack strength and ultimate strength from the moment middeflection curves.

(1) The Flexural Failure Mode of Stone Slab with Screw-Thread Steels. When the reinforcement ratio is small, the failure mode of the stone slab with screw-thread steels is the brittle mode. The brittle failure mode can be divided into two phases: elastic phase before cracking (A) and failure phase

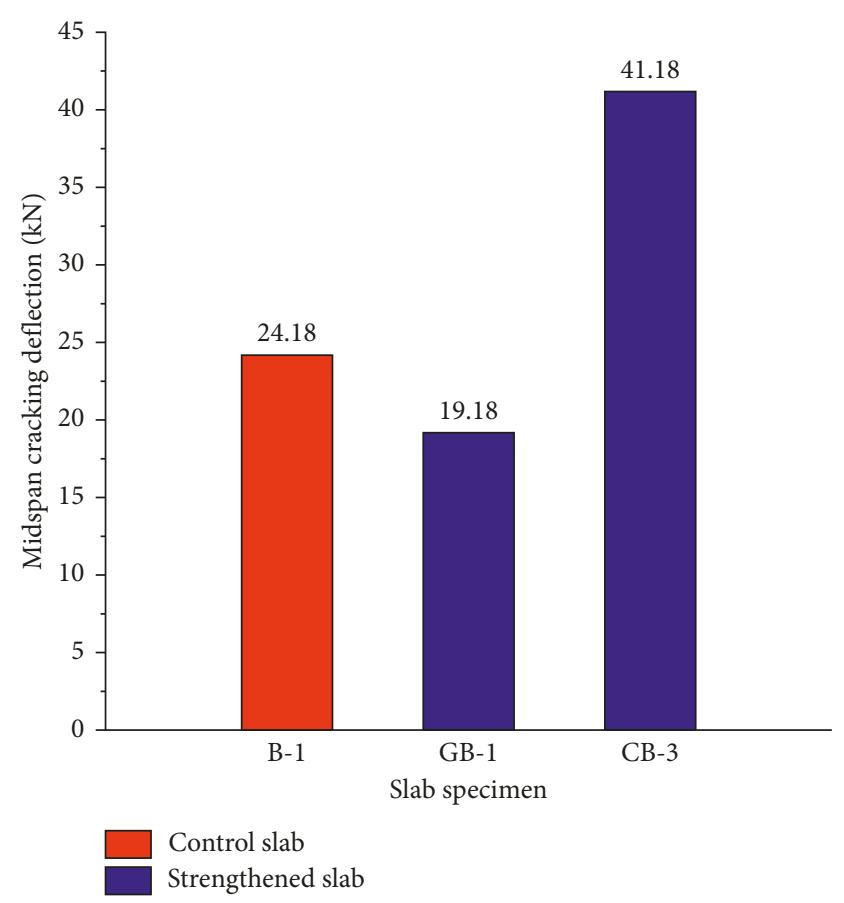

FIgURe 47: Ultimate load.

after cracking (B) (Figure 48(a)). The cross-sectional stress profile of the brittle mode is shown in Figure 49(a). When the reinforcement ratio is large, the failure mode of the stone slab with screw-thread steels is a ductility failure mode, and the ductility failure mode can be divided into three phases: elastic phase before cracking (A), from the appearance of crack to yielding of screw-thread steels after cracking (B), and failure phase (C) (Figure 48(b)). The cross-sectional stress profile is shown in Figure 49(b).

(2) The Flexural Failure Mode of Stone Slab with CFRP. When the reinforcement ratio is small, the failure mode of the stone slab with CFRP is the brittle mode, and two phases of the brittle mode and the cross-sectional stress profile of the brittle mode was the same as the stone slab with screwthread steels (Figures 48(a) and 49(a)). When the reinforcement ratio is large, the failure mode of the stone slab with FRP is also the brittle failure mode, and the brittle failure mode can be divided into two phases: elastic phase before cracking and failure phase after cracking (Figure 50). The cross-sectional stress profile of the brittle mode is shown in Figure 51.

\subsubsection{The Flexural Capacity of Stone with NSM Screw-Thread Steels and CFRP}

(1) Basic Assumptions. The following assumptions about the flexural capacity of the stone slab with NSM screw-thread steels and CFRP were made:

(1) The strain distribution of the cross section for the stone slab with NSM screw-thread steels and CFRP satisfied the plane section assumptions before 


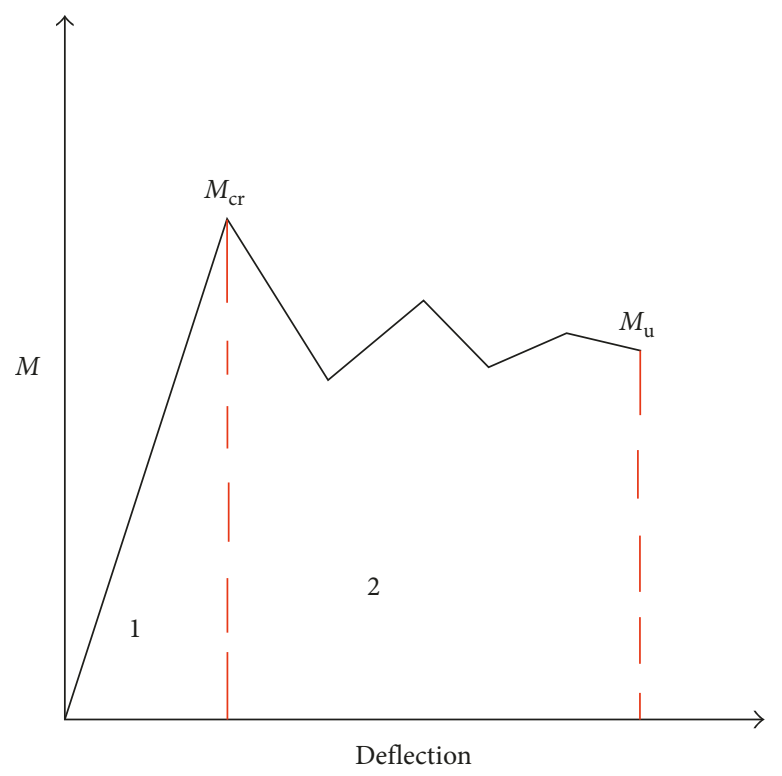

(a)

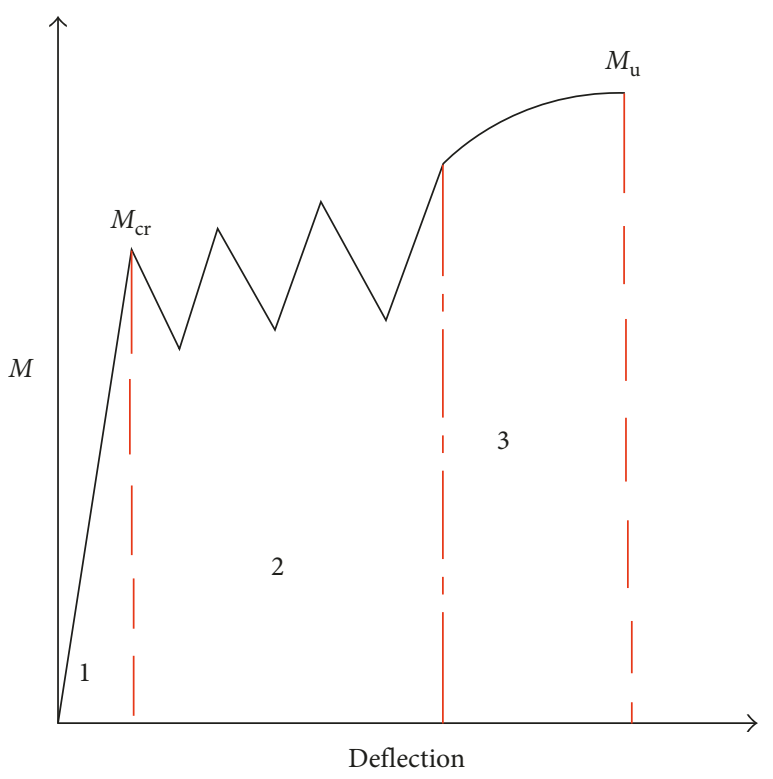

(b)

FIGURE 48: Failure process of the stone slab with NSM screw-thread steels: (a) brittle failure mode and (b) ductility failure mode.



(a)

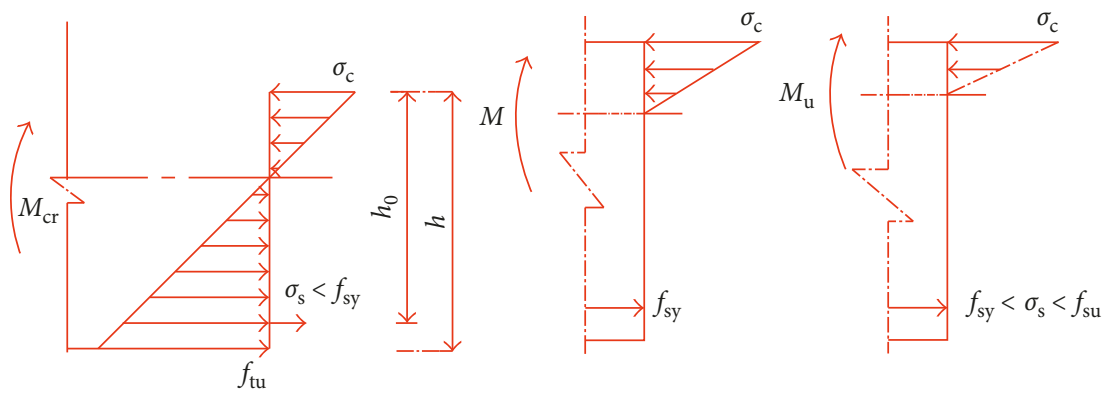

(b)

FiguRE 49: Cross-sectional stress profile of the stone slab with NSM screw-thread steels. (a) The cross section stress profile of brittle failure mode: (A) elastic phase before cracking and (B) failure phase after cracking. (b) The cross section stress profile of ductility failure mode: (A) elastic phase before cracking, (B) from the appearance of crack to yielding of screw-thread steels after cracking, and (C) failure phase.

cracking, not satisfying the plane section assumptions after cracking.

(2) The adhesion between the stone slab and screwthread steels or CFRP was reliable, not considering the relative sliding.
(3) The effect of shear deformation on the flexural capacity was not considered.

(4) The tensile and flexural effect of structural adhesive on the flexural capacity was considered before cracking. 


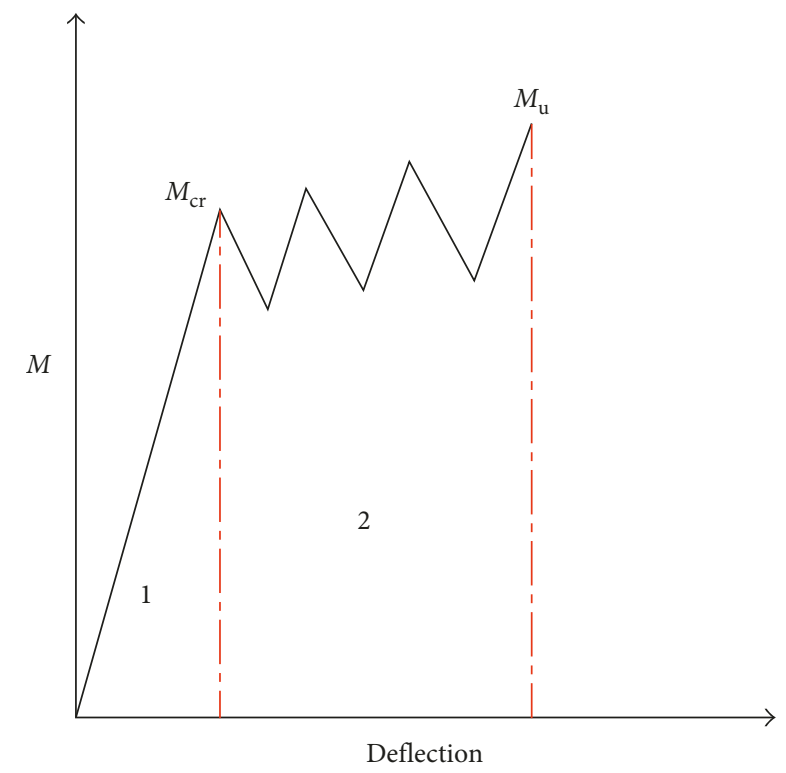

FIgURE 50: Failure process of the stone slab with NSM CFRP.

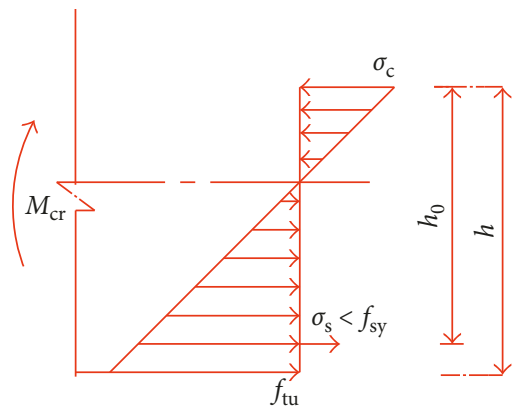

(a)

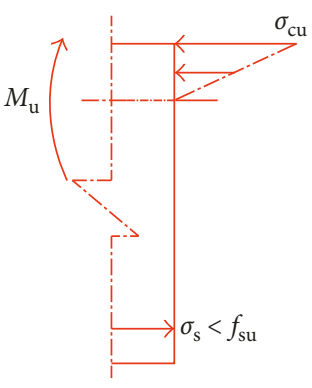

(b)
FIGURE 51: Cross-sectional stress profile of the stone slab with NSM CFRP: (a) elastic phase before cracking and (b) failure phase after cracking.

(5) The stress-strain curves of CFRP and screw-thread steels, respectively, satisfied the linear elastic relationship and the ideal elastic-plastic relationship.

(6) The stress-strain curve of stone materials was in accordance with linear elastic relationship. The maximum stress of the failure section for the stone slab was equal to ultimate strength of the stone material.

(2) Calculation of Cracking Strength. From experiment phenomenon and analysis of the failure mode, we can conclude that before cracking, the stone slab with NSM screw-thread steels or CFRP was in the linear elastic phase. When the cracking loading was attained, the stone slab was cracked in the tension zone of the cross section. Meanwhile, the compressive zone of the stone slab and the strain of screw-thread steels and CFRP were in the linear elastic phase. According to plane section assumption and stress-strain relationship, the mode of calculation about cracking strength of the stone slab is shown in Figure 52.
According to the basic assumption, the tensile force of the stone slab in the tension zone was jointly borne by the stone slab, screw-thread steels, and high-strength epoxy resin. Therefore, according to the internal force equilibrium of the cross section,

force equilibrium:

$$
\frac{1}{2} \sigma_{\mathrm{t}} b\left(h-x_{\mathrm{cr}}\right)+\sigma_{\mathrm{s}} A_{\mathrm{s}}+\sigma_{\mathrm{j}} A_{\mathrm{j}}=\frac{1}{2} b x_{\mathrm{cr}} \sigma_{\mathrm{c}}
$$

moment equilibrium:

$$
\begin{aligned}
M_{\mathrm{cr}}= & \frac{1}{3} \sigma_{\mathrm{t}} b\left(h-x_{\mathrm{cr}}\right)+\frac{1}{3} \sigma_{\mathrm{c}} b h x_{\mathrm{cr}}+\sigma_{\mathrm{s}} A_{\mathrm{s}}\left(h_{0}-\frac{x_{\mathrm{cr}}}{3}\right) \\
& +\sigma_{\mathrm{j}} A_{\mathrm{j}}\left(h_{0}-\frac{x_{\mathrm{cr}}}{3}\right) .
\end{aligned}
$$

where $h$ is the section total height of the stone slab; $\sigma_{\mathrm{s}}$ is the distance between the bottom of the stone slab and resulting force of steels; $h_{0}$ is the section effective height, $h_{0}=h-\sigma_{\mathrm{s}}$; and $b$ is the section width of the stone slab.

According to the stress-strain relationship, the following equality is satisfied:

$$
\begin{gathered}
\sigma_{\mathrm{t}}=E_{\mathrm{t}} \varepsilon_{\mathrm{t}}, \\
\sigma_{\mathrm{s}}=E_{\mathrm{s}} \varepsilon_{\mathrm{s}}, \\
\sigma_{\mathrm{c}}=E_{\mathrm{c}} \varepsilon_{\mathrm{c}}, \\
\sigma_{\mathrm{j}}=E_{\mathrm{j}} \varepsilon_{\mathrm{j}},
\end{gathered}
$$

where $E_{\mathrm{c}}$ is the compressive elastic modulus of the stone slab, $E_{\mathrm{t}}$ is the tensile elastic modulus of the stone slab, $E_{\mathrm{s}}$ is the elastic modulus of screw-thread steels or CFRP, and $E_{\mathrm{j}}$ is the elastic modulus of structural adhesion; $x_{\mathrm{cr}}$ is the depth of the compression zone of the stone slab; $\sigma_{\mathrm{t}}$ is the tensile strength of the stone slab; $\sigma_{c}$ is the compressive strength of the stone slab; $\sigma_{j}$ is tensile strength of high-strength epoxy resin; $A_{\mathrm{s}}$ is the area of steels; and $A_{\mathrm{j}}$ is the area between steels and high-strength epoxy resin.

According to the plane section assumption, the relationship among strain is as follows:

$$
\begin{aligned}
& \frac{\varepsilon_{\mathrm{c}}}{\varepsilon_{\mathrm{t}}}=\frac{x_{\mathrm{cr}}}{h-x_{\mathrm{cr}}}, \\
& \frac{\varepsilon_{\mathrm{s}}}{\varepsilon_{\mathrm{t}}}=\frac{h_{0}-x_{\mathrm{cr}}}{h-x_{\mathrm{cr}}}, \\
& \frac{\varepsilon_{\mathrm{j}}}{\varepsilon_{\mathrm{t}}}=\frac{h_{0}-x_{\mathrm{cr}}}{h-x_{\mathrm{cr}}},
\end{aligned}
$$

where $\varepsilon_{\mathrm{c}}$ and $\varepsilon_{\mathrm{t}}$ are, respectively, compressive strain and tensile strain of the stone slab and $\varepsilon_{\mathrm{s}}$ and $\varepsilon_{\mathrm{j}}$ are, respectively, the tensile strain of steels and tensile strain of high-strength epoxy resin.

The edge mean strain of the stone slab in the compression zone and the mean strain of screw-thread steels can 


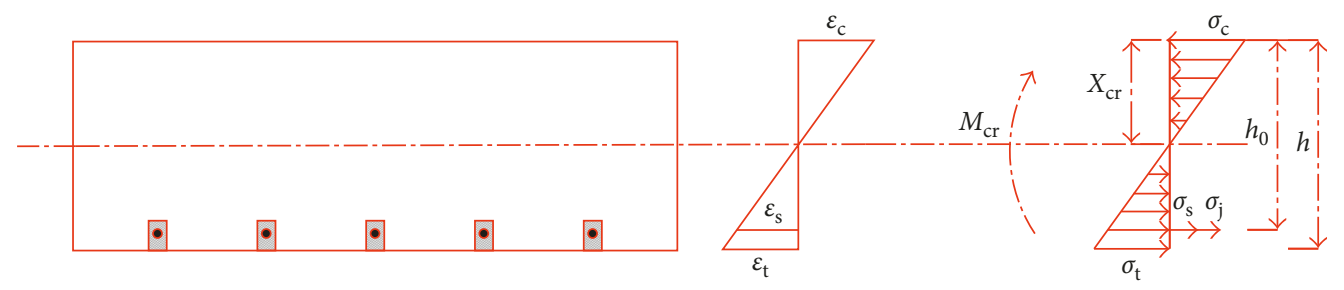

FIgURE 52: The strain and stress profile of the cross section.

TABLe 11: Calculation of internal equilibrium of the stone slab.

\begin{tabular}{lcccccc}
\hline Label of specimen & $\varepsilon_{\mathrm{t}}(\mu \varepsilon)$ & $\varepsilon_{\mathrm{s}}(\mu \varepsilon)$ & $\varepsilon_{\mathrm{c}}(\mu \varepsilon)$ & $X_{\mathrm{cr}}(m m)$ & $F_{\mathrm{t}}(k N)$ & $F_{\mathrm{c}}(k N)$ \\
\hline CB-1 & 459 & 307 & 225 & 46.11 & 117.06 & 116.82 \\
CB-2 & 532 & 456 & 267 & 46.73 & 140.12 & 140.49 \\
CB-3 & 535 & 350 & 272 & 47.19 & 144.07 & 1.00 \\
GB-1 & 447 & 374 & 239 & 48.82 & 131.09 & 1.00 \\
GB-2 & 440 & 367 & 240 & 49.39 & 132.93 & 131.38 \\
GB-3 & 418 & 366 & 232 & 49.97 & 130.17 & 1.00 \\
GB-4 & 508 & 406 & 281 & 49.86 & 157.29 & 1.00 \\
GB-5 & 487 & 456 & 274 & 51.32 & 157.82 & 1.54 \\
GB-6 & 558 & 477 & 334 & 52.31 & 197.84 & 1.00 \\
\hline
\end{tabular}

Note. $F_{\mathrm{t}}$, tensile force of the cross section for the stone slab; $F_{\mathrm{c}}$, compressive force of the cross section for the stone slab.

TABLE 12: Calculation of the cracking moment.

\begin{tabular}{|c|c|c|c|c|c|c|c|c|c|}
\hline Label of specimen & $M_{\mathrm{cr} 1}$ & $M_{\mathrm{cr} 2}$ & $M_{\mathrm{cr}}$ & $M_{\mathrm{crl}} / M_{\mathrm{cr}}$ & Average value & Variance & $M_{\mathrm{cr} 2} / M_{\mathrm{cr}}$ & Average value & Variance \\
\hline CB-1 & 10.28 & 11.13 & 11.07 & 0.93 & & & 1.01 & & \\
\hline CB-2 & 12.14 & 13.42 & 13.54 & 0.90 & & & 0.99 & & \\
\hline CB-3 & 12.16 & 13.86 & 12.78 & 0.95 & & & 1.08 & & \\
\hline GB-1 & 10.67 & 12.78 & 13.82 & 0.77 & & & 0.92 & & \\
\hline GB-2 & 10.43 & 12.92 & 12.61 & 0.83 & 0.85 & 0.07 & 1.02 & 1.02 & 0.07 \\
\hline GB-3 & 9.95 & 12.82 & 12.67 & 0.79 & & & 1.01 & & \\
\hline GB-4 & 11.93 & 15.34 & 15.38 & 0.78 & & & 1.00 & & \\
\hline GB-5 & 12.35 & 15.56 & 15.64 & 0.79 & & & 1.00 & & \\
\hline GB-6 & 15.14 & 19.63 & 16.94 & 0.89 & & & 1.16 & & \\
\hline
\end{tabular}

Note. $M_{\mathrm{cr} 1}$, cracking moment not considering the action of structural adhesive; $M_{\mathrm{cr} 2}$, cracking moment not considering the action of structural adhesive; $M_{\mathrm{cr}}$, experimental value of the cracking moment.

be obtained from the experimental results; meanwhile, the ultimate tensile strength of structural adhesives $\left(f_{\mathrm{tj}}\right)$ was achieved when the stone slab cracked. So, the height of the compression zone of the stone slab $\left(X_{\mathrm{cr}}\right)$ can be calculated according to (1), as shown in Table 11, and the cracking moment can be obtained by substitution of the height of the compression zone of the stone slab into (2), as shown in Table 12.

\section{(3) Calculation of Ultimate Strength}

(a) Calculation of ultimate moment of stone slab with NSM screw-thread steels

For the components GB-1 4 which was in the brittle failure mode, the ultimate moment was much less than the cracking moment. Although the stone slab had a certain flexural capacity after cracking, this part of strength cannot be utilized. So we assumed that the ultimate strength was equal to cracking strength for the brittle failure mode of GB-1 4.
For the ductility failure mode, the stress profile of the cross section is shown in Figure 53.

According to the internal force equilibrium of the cross section, the ultimate moment of the stone slab with NSM screw-thread steels was calculated as follows:

$$
\begin{aligned}
& \sum N=0, \frac{1}{2} f_{\mathrm{cu}} b x_{\mathrm{u}}=\sigma_{\mathrm{s}} A_{\mathrm{s}}, \\
& \sum M=0, M_{\mathrm{u}}=\sigma_{\mathrm{s}} A_{\mathrm{s}}\left(h_{0}-\frac{x_{\mathrm{u}}}{3}\right),
\end{aligned}
$$

where $f_{\mathrm{cu}}$ is the ultimate compressive strength of the stone slab, $M_{\mathrm{u}}$ is the ultimate moment, and $x_{\mathrm{u}}$ is the ultimate height of the compressive zone of the stone slab.

According to the steel's strain measured, the yield strength of the steels was achieved when the stone slab was destroyed, so the ultimate moment can be calculated according to the compressive height of cross section measured, as shown in Table 13. 


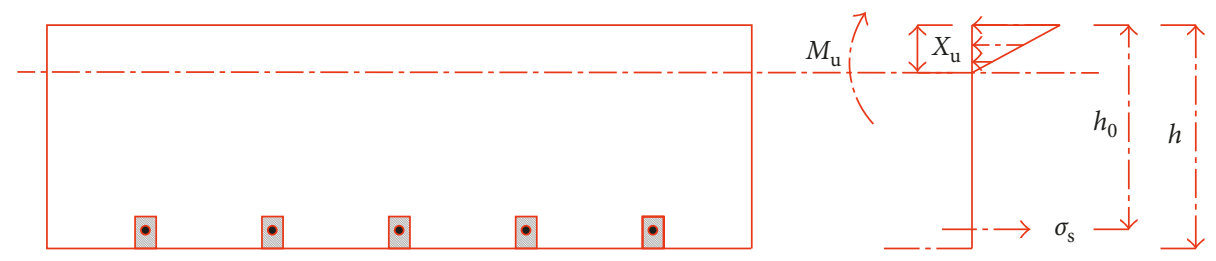

Figure 53: The stress profile of the cross section of the stone slab with the ultimate moment.

TABLE 13: Calculation of the cracking moment.

\begin{tabular}{lcccc}
\hline Label of specimen & $x_{\mathrm{u}}$ & $M_{\mathrm{u}}(\mathrm{kN} \cdot \mathrm{m})$ & $\overline{M_{\mathrm{u}}}(\mathrm{kN} \cdot \mathrm{m})$ & $M_{\mathrm{u}} / \bar{M}_{\mathrm{u}}$ \\
\hline GB-5 & 6.53 & 14.14 & 17.44 & 0.81 \\
GB-5 & 9.84 & 19.57 & 25.49 & 0.77 \\
\hline
\end{tabular}

Note. $M_{\mathrm{u}}$, calculated value of the failure moment; $\overline{M_{\mathrm{u}}}$, measured value of the failure moment.

\section{(b) Calculation of ultimate moment of stone slab with NSM CFRP bars}

For the component which had a small reinforcement ratio (CB-1), the failure characteristic of CB-1 was similar to GB-1 5. So, we assumed that the ultimate moment of CB-1 was equal to the cracking moment of CB-1. In the next section, we only calculated the ultimate moment of CB-2 and CB-3. The failure mode of $\mathrm{CB}-2 \sim 3$ was the brittle failure mode, and this was caused by the properties of the CFRP bar which has low elastic modulus and high strength. That is to say, once the stone slab with NSM CFRP was cracked, the ultimate strength was attained rapidly, and then the CFRP bars broke.

We assumed that when the stone slab with NSM CFRP bars failed, the ultimate strength of the stone slab in the compressive zone was achieved, and the stress of CFRP bars was obtained according to the measured value.

According to (5), we can calculate the ultimate strength, as shown in Table 14.

\section{Conclusions}

The experimental study was conducted to investigate the flexural performance of the stone slab strengthened with NSM screw-thread steels and CFRP bars. The following conclusions were made for the experimental tests:

(1) The flexural capacity and ductility of stone slab NSM screw-thread steels and FRP bars are obviously improved. Under the case of maximum reinforcement ratios, the crack load, failure load, and failure displacement of stone slab NSM screw-thread steels are increased, respectively, $10.9 \%, 167 \%$, and $617 \%$ over the control slab. So, it is very effective to improve the drawback which is brittle and weak ductility.

(2) The effect of the groove dimension on flexural capacity is evident. As the groove height increases, the cracking load and middeflection of cracking decrease by $6.4 \%$ and $8.3 \%$ over the control slab, respectively;
TABLE 14: Ultimate strength of CB-2 and CB-3.

\begin{tabular}{lccc}
\hline Label of specimen & $M_{\mathrm{u}}(\mathrm{kN} \cdot \mathrm{m})$ & $\overline{M_{\mathrm{u}}}(\mathrm{kN} \cdot \mathrm{m})$ & $M_{\mathrm{u}} / \bar{M}_{\mathrm{u}}$ \\
\hline CB-2 & - & 17.03 & - \\
CB-3 & 18.01 & 18.53 & 0.97 \\
\hline
\end{tabular}

Note. $M_{\mathrm{u}}$, calculated value of the failure moment; $\overline{M_{\mathrm{u}}}$, measured value of the failure moment. The CB-2's ultimate strength was not measured because the strain gauge was damaged.

the failure load and middeflection of failure increase by $4.7 \%$ and $6.4 \%$ over the control slab, respectively. As the groove width increases, the cracking load and middeflection of cracking decrease by $8.3 \%$ and $14.18 \%$ over the control slab, respectively; the failure load and middeflection of failure increase by $20 \%$ and $41.2 \%$ over the control slab, respectively.

(3) The effect of reinforcement ratios on the flexural capacity of the stone slab is obvious. The crack load, failure load, and failure deflection are increased obviously with the increase of reinforcement ratios. The joint work performance can be improved with the increase of reinforcement ratios. The strength of the stone material and steel bars of CFRP bars can be fully utilized by increasing reinforcement ratios.

(4) The reinforcement ratio can control the failure mode. When the reinforcement ratios were low, the failure mode of the stone slab was brittle failure, and when the reinforcement ratios were high, the failure mode of the stone slab was ductility failure and thus multicracking was formed. This is similar to the failure mode of concrete member NSM steel bars.

(5) From the point of view of strain for screw-thread steels, CFRP bars, and stone slabs, we can analyze the whole failure process, and a corresponding relationship is formed with the failure mode.

(6) Before cracking, the stone slab with NSM screw-thread steels and CFRP bars satisfied plane section assumption. Neutral axis height is invariant under the case of changing the grooving dimension. The neutral axis decreases with the increase of reinforcement ratios.

(7) Before cracking, the joint work performance is very well. After cracking, the stone slab exits work; the load is borne by screw-thread steels and CFRP bars; and the slip displacement generates between the stone slab, screw-thread steels, and CFRP bars. The slip displacement is very small. So, the joint work performance is still very great. 
(8) Comparing stone slabs with NSM screw-thread steels with NSM CFRP bars, the CFRP bars are more effective to resist the flexural loading than the screw-thread steels under the same reinforcement ratios and groove dimensions. Meanwhile, under the case of low reinforcement ratios, the stone slab NSM screw-thread steels generate debonding failure, but the stone slab NSM CFRP bars does not.

(9) The calculation results of strength are in agreement with the experimental results.

\section{Conflicts of Interest}

The authors declare no conflicts of interest.

\section{Authors' Contributions}

Xiaopeng Gao wrote the manuscript. Xiaopeng Gao, Zhongfan Chen, Xiaomeng Ding, and Erxiang Dong designed the experiments. Xiaopeng Gao modified the final paper.

\section{Acknowledgments}

This research was supported by the National "Twelfth FiveYear" Plan for Science and Technology Support of China (no. 2015BAL03B02-02).

\section{References}

[1] D. L. Lorenzis and A. Nanni, "Characterization of FRP rods as near-surface mounted reinforcement," Journal of Composites for Construction, vol. 5, no. 2, pp. 114-121, 2001.

[2] D. L. Lorenzis and A. Nanni, "Shear strengthening of reinforced concrete beams with near-surface mounted fiberreinforced polymer rods," ACI Structural Journal, vol. 98, pp. 60-68, 2001.

[3] V. Turco, S. Secondin, A. Morbin, M. R. Valluzzi, and C. Modena, "Flexural and shear strengthening of unreinforced masonry with FRP bars," Composites Science and Technology, vol. 66, no. 2, pp. 289-296, 2006.

[4] X. Qingfeng, C. Lingzhu, K. A. Harries, Z. Fuwen, W. Zhuolin, and C. Xi, "Experimental study and numerical simulation of long-term behavior of timber beams strengthened with near surface mounted CFRP bars," Materials and Structures, vol. 50, no. 1, p. 45, 2017.

[5] Y. Wei, M. Q. Zhou, and D. J. Chen, "Flexural behavior of glulam bamboo beams reinforced with near-surface mounted steel bars," Materials Research Innovations, vol. 19, no. 1, pp. S98-S103, 2015.

[6] E. I. Saqana, H. A Rasheed, and T. Alkhrdaji, "Evaluation of the seismic performance of reinforced concrete frames strengthened with CFRP fabric and NSM bars," Composite Structures, vol. 184, pp. 839-847, 2018.

[7] S. O. Asplund, "Strengthening bridge slabs with grouted reinforcement," Journal of the American Concrete Institute, vol. 20, pp. 397-406, 1949.

[8] S. W. Garrity, "Near-surface reinforcement of masonry arch highway bridges," in Proceedings of the 9th Canadian Masonry Symposium, Fredericton, Canada, June 2001.

[9] J. M. D. S. Cruz and J. A. O. D. Barros, "Bond between nearsurface mounted carbon-fiber-reinforced polymer laminate strips and concrete," Journal of Composites for Construction, vol. 8, no. 6, pp. 519-527, 2004.

[10] T. Hassan and S. Rizkalla, "Investigation of bond in concrete structures strengthened with near surface mounted carbon fiber reinforced polymer strips," Journal of Composites for Construction, vol. 7, no. 3, pp. 248-257, 2003.

[11] L. D. Lorenzis, A. Rizzo, and A. L. Tegola, "A modified pullout test for bond of near-surface mounted FRP rods in concrete," Composites Part B: Engineering, vol. 33, no. 8, pp. 589-603, 2002.

[12] G. Sakara, R. A. Hawileh, M. Z. Naser, J. A. Abdalla, and M. Tanarslan, "Nonlinear behavior of shear deficient RC beams strengthened with near surface mounted glass fiber reinforcement under cyclic loading," Materials and Design, vol. 61, pp. 16-25, 2014.

[13] K. M. U. Darain and H. Akter, "Strengthening of RC beams using externally bonded reinforcement combined with nearsurface mounted technique," Polymers, vol. 8, no. 7, p. 261, 2016.

[14] R. Kotynia and S. Cholostiakow, "New proposal for flexural strengthening of reinforced concrete beams using CFRP T-shaped profiles," Polymers, vol. 7, no. 11, pp. 2461-2477, 2015.

[15] H. A. Rasheed, R. R. Harrison, R. J. Peterman et al., "Ductile strengthening using externally bonded and near surface mounted composite systems," Composite Structures, vol. 92, no. 10, pp. 2379-2390, 2010.

[16] R. A. Hawileh, "Nonlinear finite element modeling of RC beams strengthened with NSM FRP rods," Construction and Building Materials, vol. 27, no. 1, pp. 461-471, 2012.

[17] L. D. Lorenzis and J. G. Teng, "Near-surface mounted FRP reinforcement: an emerging technique for strengthening structures," Composites Part B: Engineering, vol. 38, no. 2, pp. 119-143, 2007.

[18] P. Azadeh and S. S. Taqiuddin, "Fiber reinforced polymer strengthening of structures by near-surface mounting method," Polymers, vol. 8, no. 8, p. 298, 2016.

[19] R. Elhacha and K. Soudki, "Prestressed near-surface mounted fiber reinforced polymer reinforcement for concrete structures a review," Canadian Journal of Civil Engineering, vol. 40, no. 11, pp. 1127-1139, 2013.

[20] R. Parretti and A. Nanni, "Strengthening of RC members using near-surface mounted FRP composites design overview," Advances in Structural Engineering, vol. 7, no. 6, pp. 469-483, 2004.

[21] China Industry Standard, Seismic Technical Specification for Building Construction in Town and Village, JGJ161-2008, China Architecture and Building Press, Beijing, China, 2011.

[22] China Industry Standard, Code for Seismic Design of Buildings, GB50003-2011, China Architecture and Building Press, Beijing, China, 2011.

[23] China Industry Standard, Code for Design of Masonry Structures, GB50003-2011, China Architecture and Building Press, Beijing, China, 2011.

[24] British Standard Institute (BSI), Testing Hardened Concrete, Tensile Splitting Strength of Test Specimens, BS EN 12390-6, BSI, London, UK, 2000.

[25] America Society for Testing and Materials (ASTM), Standard Test Method for Static Modulus of Elasticity and Poisson Ratio of Concrete in Compression, C469, ASTM, West Conshohocken, PA, USA, 2002.

[26] America Society for Testing and Materials (ASTM), Standard Test Methods and Definitions for Mechanical Testing of Steel Products, A370-17, ASTM, West Conshohocken, PA, USA, 2017. 
[27] G. Zhenhai, Principles of Reinforced Concrete, Tsinghua University Press, Beijing, China, 1st edition, 2014.

[28] M. M. Rafi, A. Nadjai, F. Ali, and D. Talamona, "Aspects of behavior of CFRP reinforced concrete beams in bending," Construction and Building Materials, vol. 22, no. 3, pp. 277285, 2008.

[29] M. A. Hosen, U. J. Alengaram, M. Z. Jumaat, and N. H. R. Sulong, "Glass Fiber Reinforced Polymer (GFRP) bars for enhancing the flexural performance of RC beams using side-NSM technique," Polymer, vol. 9, no. 12, p. 180, 2017.

[30] M. Hosen, M. Jumaat, U. Alengaram, A. Islam, and H. Hashim, "Near surface mounted composites for flexural strengthening of reinforced concrete beams," Polymer, vol. 8, no. 3, p. 67, 2016. 


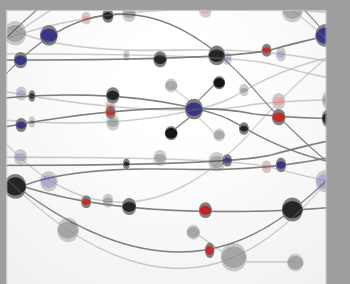

The Scientific World Journal
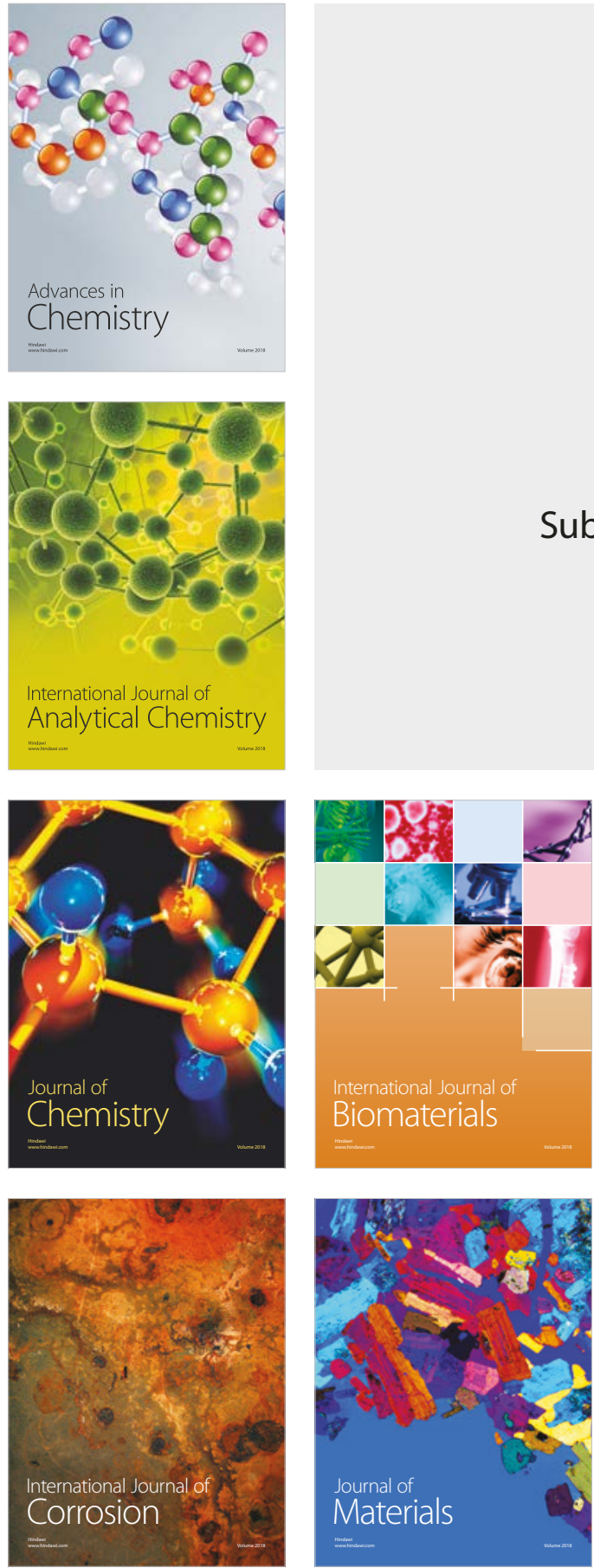

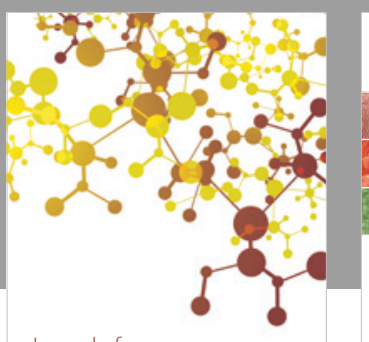

Journal of

Applied Chemistry


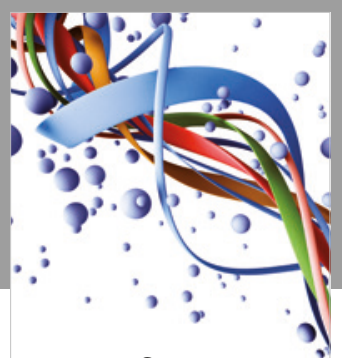

Scientifica

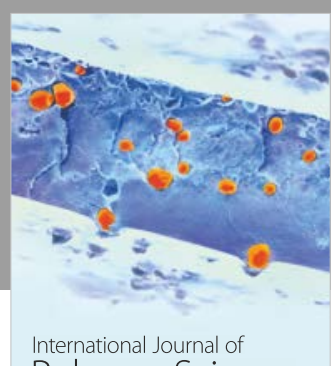

Polymer Science



Physical Chemistry
